\title{
Politik und Religion in Europa
}

mit Beiträgen von Orlando Budelacci und

Gabriel N. Toggenburg 
Das Europainstitut der Universität Basel ist ein rechts-, politik- und wirtschaftswissenschaftliches Zentrum für interdisziplinäre Lehre und Forschung zu europäischen Fragen. Neben einem einjährigen, praxisbezogenen und interdisziplinären Nachdiplomstudium zum Master of Advanced European Studies werden spezielle Weiterbildungskurse angeboten. In der Forschung werden in Zusammenarbeit mit benachbarten Instituten sowohl fachspezifische wie multidisziplinäre Themen bearbeitet. Das Europainstitut ist als Ansprechpartner für Politik, Wirtschaft und Verwaltung beratend tätig.

Orlando Budelacci, Dr. phil., Assistent der Institutsleitung des Europainstituts der Universität Basel. Studium der Philosophie, Kunst- und Rechtswissenschaften an der Universität Basel.

Gabriel N. Toggenburg, Mag.iur., LL.M.; wissenschaftlicher Mitarbeiter an der Europäischen Akademie Bozen/Bolzano (http://www.eurac.edu) und PhD researcher am European University Institute Florence (http://www.iue.it). Anstoß zu diesem Aufsatz war ein an der Evangelischen Akademie im Rheinland gehaltener Vortrag.

\section{Inhaltsverzeichnis}

\section{Orlando Budelacci}

Politik und Religion im postmetaphysischen Europa

\section{Gabriel N. Toggenburg}

Der (dritte) Weg zur (v)erfassbaren Religionsidee der EU 


\section{Orlando Budelacci}

\section{Politik und Religion im postmetaphysischen Europa}

Wer dachte, dass Nihilismus und Säkularisation ihren Siegeszug angetreten haben und die Religion eine überwundene Grösse im Kontext des Politischen ist, kann leicht widerlegt werden. Nicht nur die terroristischen Fundamentalismen handeln in Gottes Namen, auch Staatspräsidenten bemühen ihn, um ihren aussenpolitischen Missionarismus und ihre geopolitischen Interessen zu legitimieren. Es ist einfacher, Kriege im Names Gottes zu führen. Und auch nach der längst vergangenen Proklamation des Gottestodes durch Friedrich Nietzsche ist die Anrufung Gottes selbstverständlicher Teil der Altagspolitik und oft unsichtbarer - Unterbau der abendländischen Kultur geblieben. So hat z.B. der Schweizer Bundesrat Christoph Blocher seine Annnahme des Bundesratsamtes mit den Worten beendet, "dass Gott uns helfe, dass es gut herauskommt“. Wir begegnen in der Politik vielen zivilreligiösen Gesten, wie beispielsweise den politischen Entschuldigungsritualen, durch die wir an die christliche Herkunft unserer Gegenwartskultur erinnert werden. ${ }^{1}$ Besonders die politische Kultur der USA ist durch eine Vielzahl von expliziten aber auch impliziten religiösen Bekenntnissen geprägt. ${ }^{2}$ Bei Verfassungsrevisionen wird darüber gestritten, ob eine invocatio dei die Präambel einleiten soll oder gänzlich darauf verzichtet werden soll. ${ }^{3}$ Zugleich ist für viele unmöglich geworden, dass der weltanschaulich neutrale Rechtsstaat, der auch die Religionsfreiheit garantiert, sich vor Gott verantworten soll und in Verfassungspräambeln, wie im Entwurf eines Vertrags über eine Verfassung für Europa, zwar nicht auf Gott oder das Christentum, aber auf die Rolle der Religion für die kulturgeschichtliche Entwicklung Europas hingewiesen wird. ${ }^{4}$ In der laizistischen Ablehnung dieses Hinweises sind noch Reaktionen auf die historische Erfahrungen der religiösen Politikintervention lebendig, die die Vermischung von Religion und Politik als Gefahr für den modernen Rechtsstaat betrachten.
Die Funktion der Religion wurde vom Linkshegelianer Ludwig Feuerbach analysiert, der diese als Erfindung des Menschen und als ein psychohygienisches Bedürfnis gedeutet hat: „Der wesentliche Standpunkt der Religion ist der praktische, d.h. hier der subjektive. Der Zweck der Religion ist das Wohl, das Heil, die Seligkeit des Menschen." ${ }^{5}$. Bei Karl Marx dient die Religion dem illusorischen Glück des Volkes; sie ist "Opium des Volkes“6. Und gemäss Friedrich Nietzsche wurde Gott von den Schwachen erfunden. ${ }^{7}$ Eine andere Sichtweise finden wir bei Machiavelli, der den Nutzen der Religion für die Stabilisierung des Staates (mantenere lo stato) betont und demzufolge ihre identitätsstiftende Funktion politisch instrumentalisieren möchte. Der uomo virtuoso muss die religiösen Grundlagen des Volkes erhalten, damit dieses einträchtig bleibt: Religion ist wertvoll, weil sie der Politik dient. ${ }^{8}$

Die religiösen Elemente im modernen Rechtsstaat werden gegen laizistische Vorwürfe mit dem Argument verteidigt, dass die Anrufung Gottes lediglich als Chiffre für die Selbstrelativierung politischer Macht zu deuten ist und daher kein Glaubensbekenntnis sein muss. Religion als Politikentlastung, dies eine weitere Variante, mit der die Religion als „indirekt stützende Daseinsmacht“" der Politik betrachtet wird. ${ }^{10}$ Diesen Betrachtungen stehen die Forderungen nach einem laizistischen Staat entgegen, der - wie es sich beispielsweise im vieldiskutierten Kopftuchverbot zeigt - religiöse Symbole vollständig aus ihrem Bezug zum Staat und seinen Institutionen herauslösen möchte. Der Staat soll religiös neutral sein und lediglich die Religion als Privatsache garantieren. Über diese Einzelargumente und umstrittenen gegenwärtigen Diskussionen hinaus beschäftigt sich dieser Beitrag in grundsätzlicher Weise mit folgenden Fragen: Was sind die Auswirkungen des Transzendenzverlustes für das Politische? Führt die Säkularisierung zu einer Verlagerung ehemals theologischer Gehalte auf den Staat? Stimmt es, dass wir eine Renaissance der Religion erleben und dass der Staat durch die Übertragung religiöser Ansprüche auf den Staat 
überfordert wird? Es geht also nicht primär um die Frage, ob der Staat Orientierung in existenziellen Fragen liefern soll, sondern inwiefern die Religion, ob verdrängt oder in anderem Gewand erscheinend, im Politischen präsent ist. Die Argumentation zeigt durch die Analyse der Verschiebungen religiöser Ansprüche ins Politische, dass dies zu vielfältigen Problemkonstellationen führt, die bei einer Überwindung des Religiösen im Politischen berücksichtigt werden müssen. Das Aufzeigen der negativen Auswirkungen des Transzendenzverlustes ist kein Plädoyer für die Wiederherstellung von Transzendenz und kein Einwand gegen den weltanschaulich neutralen Rechtsstaat. Der Beitrag versteht sich als propädeutisch hinsichtlich der Herstellung von Problemund Situationsbewusstsein. Es soll durch die Darstellung verdeutlicht werden, dass Säkularisierungs- und Aufklärungsprozesse stets auch von ihren Antipoden begleitet werden. Die negativen Konsequenzen werden fokussiert, nicht um die positiven zu marginalisieren, sondern um die Einseitigkeit zu kontrastieren, mit der oft argumentiert wird. Diese Präzisierungen sind notwendig, wenn das politische Europa die Erschütterungen, die durch den Verlust der alten Ordnung bewirkt wurden, überwinden möchte und sich jenseits des Religiösen ein Fundament für die politische Zukunft bauen möchte.

\section{Transzendenzverlust und die Renaissance der Religion}

Im postmetaphysischen Europa haben Transzendenzbezüge ihre Selbstverständlichkeit verloren. Gott ist, so lesen wir bei Friedrich Nietzsche, tot. Er wurde aber nicht vom Philosophen getötet, sondern von den Gläubigen. Im viel zitierten Aphorismus in der Fröhlichen Wissenschaft ist Nietzsche Seismograph und Dynamit, d.h. er verhält sich gegenüber dem Transzendenzverlust einerseits als Zeitdiagnostiker ${ }^{11}$ und zugleich hat seine Deutung des Phänomens - vor allem auch mit Blick auf seinen Angriff auf die christliche Religion - eine normative Stossrichtung. Neben weiteren Anklagen und Flüchen wirft Nietzsche dem christlichen Glauben vor, dass der Glaube an ein Jenseits das Diesseits entwerte. Nietzsche spielt auch hier das Spiel der Masken, denn das verhängnisvolle Ereignis wird nicht etwa von ihm selbst, sondern vom „tollen Menschen“ auf dem Marktplatz verkündet. ${ }^{12}$ Nietzsche deckt auf, dass die Religion ihre ursprüngliche Bedeutung als Sinnund Rechtfertigungsinstanz verloren hat und „,verkündet“, eingebettet in eine rhetorische Strategie der Verführung, dass Gott tot ist. Über den unmittelbaren Gehalt dieser Aussage impliziert sie, dass der Glaube an eine objektive Ordnung mit einem Fixstern, der die Welt gegründet hat und sie beschützt, verloren gegangen ist. Das ist eine dramatische Feststellung ${ }^{13}$, aber zugleich lässt sich aus der Tatsache, dass eine Lücke, ein luftleerer Raum, entsteht, nicht schliessen, dass man diese auch füllen muss. Sisyphus soll man sich in seiner Revolte gegen die Absurdität des Daseins als einen glücklichen Menschen vorstellen, heisst es bei Albert Camus.

Der Terminus „postmetaphysisch“ bezeichnet jenen Zustand des Orientierungsverlustes, der aus dem Transzendenzverlust resultiert. Insofern ist der postmetaphysische Zustand Europas eine Gegebenheit, die zur Neuorientierung auffordert. Die Strategie der Moderne hat zu postmodernen Konsequenzen geführt: alte Gemeinschaftserfahrungen werden durch neue ersetzt, Differenzierungen und Zersplitterungen führen zu Integrations- und Identitätsverlusten und der Einzelne entfremdet sich auf mehreren Ebenen von einer Ordnung, die durch ihre klaren Strukturen und Hierarchien gekennzeichnet war: Die Vorgegebenheit der Vormoderne wurde aufgelöst. Durch Mobilisierung und Differenzierung sind Identifikationsmöglichkeiten abgeschafft worden und zugleich neue erschaffen worden. Folkloristische Rituale, wie sie etwa im Verhalten der Fans in einem Fussballspiel zu beobachten sind, haben für viele den Gottesdienst in der Kirche ersetzt. Vorbei sind die Zeiten, wie es in Novalis' idealisierendem Mittelalterbild heisst, als man „die schönen Versammlungen in den geheimnisvollen 
Kirchen, die mit ermunternden Bildern geschmückt, mit süssen Düften erfüllt und von heiliger erhebender Musik belebt waren"14, besuchte. Bei Novalis hat die Konstruktion einer (vergangenen) schönen Einheit die Funktion, die Zersplitterung und Krise der Gegenwart zu betonen und ist damit Grundlage für den Aufruf zur dialektischen Überwindung und zum Aufbruch zu neuen Ufern. Die Konstruktion von Geschichte dient als Basis für die Neugestaltung der Gegenwart.

Das (Wieder-)Auftauchen von religiösen Anrufen ist eine Gegenbewegung zu diesen Zersplitterungserscheinungen und Identitätsverlusten: Der (post-)moderne Mensch ist verlassen und sucht nach einer neuen Heimat. Die Modernisierung hat Kräfte hervorgebracht, die sich gegen sie selbst richten. Der "Mythos“ Aufklärung wurde schon von Theodor W. Adorno und Max Horkheimer entmystifiziert und auf die dialektischen Tücken des Fortschrittsglaubens hingewiesen. ${ }^{15}$ Atavismen und Fundamentalismen begleiten diesen Prozess und sind als Ablehnung der Modernisierung zu deuten, die den Sinnverlust in den fortschrittlichen Gesellschaften institutionalisiert hat. Dieser Verlust an Orientierung hat den modernen Menschen anfällig für Totalitarismen gemacht hat. ${ }^{16}$

Der Verlust Gottes als letzte Referenz, als tranzendenter Bezugspunkt, führt auch den Staat in eine Legitimationskrise und dadurch zu einem Wandel des Legitimationsmodus. Was vorher durch Gott legitimiert und in seinem Zusammenhang garantiert wurde, geriet in die Hände des Menschen, der zum bestimmenden Subjekt von Geschichte und Politik wird. „Diese ungeteilte Substanz der absoluten Freiheit erhebt sich auf dem Thron der Welt, ohne dass irgendeine Macht inr Widerstand zu leisten vermöchte." ${ }^{17}$ Hegel weist in seiner Analyse in der Phänomenologie des Geistes darauf hin, dass der Negativismus des modernen Freiheitsideals eine Macht ist, die zum Schrecken, nicht zur Befreiung führt. ${ }^{18}$
Es ist die Tradition der geschichtsphilosophischen Aufklärungsvisionen, die den Menschen zum neuen Herrn der Geschichte gekrönt hat. Der Übergang zur Freiheitsepoche korrespondiert mit einem Verantwortungszuwachs an den Einzelnen, der sich nicht nur selbst aus der Unmündigkeit befreien muss, sondern auch in autonomer Setzung sich selbst bestimmen muss. Dieser Vorgang impliziert eine Verantwortungsübertragung von Gott auf den Menschen, der zum Planer und Gestalter der Politik wird: Der Himmel wurde auf die Erde verpflanzt. ${ }^{19}$

Die Verschiebung vom Göttlichen ins Irdische öffnet die Zukunft für die autonome politische Gestaltung durch die Menschen. Normen werden nicht mehr autoritativ übernommen, sondern müssen durch autonome Setzung bestimmt werden. ${ }^{20}$ Sie gilt nicht mehr, die Vermutung für die Vernünftigkeit des Vorgegebenen. Gegenüber Traditionen und Überlieferungen wird eine kritische Position eingenommen und die Gültigkeit des Vorhandenen wird bezweifelt. Das führt auch zu zerstörerischen Prozessen und zu einem Bewusstseinsverlust für die Grenzen menschlichen Könnens und Machens.

Politisch verschiebt sich die Legitimationsidee auf die Volkssouveränität. „Der Staat ist ein Volk das sich selbst beherrscht."21, heisst es in der knappen Formulierung im handschriftlichen Nachlass von Immanuel Kant. Es ist dies die verdichtete Formel der Idee der Volksouveränität. Der Staat wird als Selbstbezugssystem gedacht, das durch keine autoritative Macht fremdbestimmt wird. Der Staat legitimiert sich durch eine Selbstsetzung des Volkes ${ }^{22}$, nicht mehr durch autoritativ vorgegebene - transzendente - Bezugspunkte..$^{23}$ Alexis de Toqueville beobachtet diesen Übergang in seiner Studie über das Prinzip der Volkssouveränität in Über die Demokratie in Amerika: „Das Volk beherrscht die politische Welt Amerikas wie Gott das Universum. Das Volk ist Anfang und Ende aller Dinge; alles geht vom Volke aus, alles in inm auf." ${ }^{24}$ 
Dieser Punkt des Umschlags wird von einer Übertragung von ehemals göttlichen Eigenschaften auf das Subjekt, den Staat oder den Souverän begleitet. Die Politische Theologie erklärt grundlegende staatspolitische Begriffe der Neuzeit durch ihre theologische Herkunft. Dabei geht es im Anschluss an Carl Schmitts „Politische Theologie“ darum, den theologischen Gehalt von säkularen Begriffen aufzudecken. ${ }^{25} \mathrm{Die}$ Omnipotenz Gottes spiegelt sich etwa in der Souveränitätslehre, die jenes Merkmal des absoluten Zuhöchstseins besitzt, das früher Gott vorbehalten war. ${ }^{26}$ Die Herkunft zentraler Begriffe des säkularen demokratischen Rechtsstaates lassen sich politisch-theologisch erklären. So hat etwa Rousseaus volonte générale ihr Äquivalent in der Allmacht Gottes. Henning Ottmann hat diese Ähnlichkeiten theologischer und politischer Begriff in einer Liste zusammengestellt. ${ }^{27}$ Oft ändert die säkulare Verwandlung des Theologischen nichts am Gehalt der Begriffe, sondern ist Ausdruck einer Verschiebung aus dem Theologischen in den säkular-politischen Bereich. Dies zeigt die tiefe Wirkung religiöser Ideen, die nach einer Metamorphose sich in anderem Gewand zeigen. „Aber es gehört zur Dialektik einer solchen Entwicklung, dass man gerade durch die Verlagerung des Zentralgebietes stets ein neues Kampfgebiet schafft. "28 Carl Schmitt weist hier in seiner aggressiven Rhetorik, die sich der Metaphern des Krieges und des Kampfes bedient, implizit auf eine zentrale Überlegung hin, die oft übersehen wird. Alleine durch die Wandlung des Begriffs, ist der Anspruch, der damit verbunden ist, noch nicht überwunden. ${ }^{29}$

\section{Der Staat als säkularer Erfüllungsgarant heilsgeschichtlicher Er- wartungen}

Nach dem Verlust der Bindungswirkung der Religion stellt sich die Frage, woraus der Staat seine integrativen Kräfte schöpft, denn ein gewisses Mass an Homogenität bzw. Identität ist notwendig, um eine konsensuale Legitimierung des Staates zu leisten. ${ }^{30}$ Demzufolge ist in der Demokratie auch ein gesamtgesellschaftlicher öffentlicher Diskurs notwendig, durch den ein Interaktionszusammenhang hergestellt wird. Fehlt dieser Interaktionszusammenhang, fehlt auch eine Grundlage für eine kollektive Identität. Auf europäischer Ebene verdichten sich zwei Problembereiche: einerseits der zunehmende Verlust der Homogenitätswirkung der Religion und andererseits das Fehlen eines gesamteuropäischen öffentlichen Raumes und einer Sprache als Vorbedingung eines solchen. Dadurch dramatisiert sich die Legitimierungsproblematik postnationaler Konstellationen bzw. von Mehrfachidentitäten, denn sowohl die Einheitsleistungen der Religion als auch die Identitätsstiftung durch das Konzept der Nation können und sollen für das neue Europa nicht mehr bemüht werden.

Viele zeitgenössische Autoren weisen auf diese Rückkehr der Religion bzw. des Religiösen hin. Samuel Huntington spricht in seinem vielbeachteten und -kritisierten Buch über den Kampf der Kulturen von einem „weltweiten Aufschwung der Religion"31 und macht den Verlust von althergebrachten Identitätsquellen für das Wiedererwachen, für die „revanche de dieu“32, verantwortlich. Gemäss dieser Logik führen Globalisierungsprozesse nicht nur in eine Richtung, sondern werden von Atavismen begleitet, die säkulare Forschrittsprozesse unterbrechen. ${ }^{33}$ Die Gegenüberstellung von Vernunft und Religion basiert auf einem bipolaren Gegensatzpaar ${ }^{34}$, das die Komplexität der tatsächlichen Beziehung nicht zu erfassen vermag und gemäss der Deutung von Jacques Derrida übersieht, dass beide derselben Quelle entspringen. ${ }^{35}$ Derrida stellt so auf der postmodernen Metaebene die bipolare Gegenüberstellung der beiden traditioneller philosophischer Kategorien der "Vernunft“ und des "Religion“ in Frage und zweifelt an der Richtigkeit der Aussage, dass es eine „Rückkehr des Religiösen“ gäbe. ${ }^{36}$ „Ich dachte im Inneren auch, dass man das Phänomen verkennt, das „Religion“ oder „Rückkehr des Religiösen“ heute genannt wird, behauptet man weiterhin auf naive Weise einen Gegensatz zwischen Ver- 
nunft und Religion, Kritik und Religion, Wissenschaft und Religion, wissenschaftstechnischer Moderne und Religion. “" ${ }^{37} \mathrm{Hegel}$ hatte in seiner Schrift Glauben und Wissen festgestellt, dass der glorreichen Sieg der aufklärenden Vernunft zu einer Veränderung der Vernunft selbst geführt hat. ${ }^{38}$ Der entscheidende Punkt dieser beiden Überlegungen ist die Tatsache, dass es "die" Religion nicht gibt und man demzufolge keine feste Grösse, die statisch festgeschrieben ist, voraussetzen kann.

Das Auflösen der Bindungswirkung der Religion führt nicht nur zu einem Wiederaufflammen religiöser Strömungen, sondern auch zu einer Delegation von heilsgeschichtlichen Erwartungen auf staatliche Akteure. Das ist problematisch, denn die Verlagerung religiöser Erwartungen auf den Staat führt zu seiner Überforderung. Überfordert wird der Staat durch die totalen Forderungen, die an inn gestellt werden. Das klingt auch im bekannten Diktum von Ernst-Wolfang Böckenförde an, demgemäss der säkularisierte Staat von Voraussetzungen lebt, die er selbst nicht garantieren kann. Durch die Totalisierung wird der Staat mit Kompetenzen ausgestattet, die sich über einen wachsenden Zuständigkeitsbereich in der Gesellschaft erstrecken. Beinahe selbstverständlich hat die Politik die Aufgaben der planvollen Organisation der Zukunftsgestaltung zu übernehmen. Die Regierbarkeit gerät so in die Krise, denn eine politische Strategie bzw. ein politisches Programm, das zur Errichtung einer vollkommenen Organisation menschlichen Lebens führen soll, muss scheitern.

Der Anspruch auf totale Gestaltungsfähigkeit überschätzt die menschliche Gestaltungsmacht und emanzipiert sich so von der Phänomenalität des Politischen, das so betrachtet wird, als ob das Zukünftige vollumfänglich verfügbar und gestaltbar ist. ${ }^{39}$ Diese Vorstellung wird auch von der zunehmenden Dominanz von Naturwissenschaft und Technik geprägt, durch die ein Verhältnis zur Natur vermittelt wird, das diese unter dem Gesichtspunkt der Verfügbarkeit für den menschlichen Nut- zen betrachtet. Religiöse Erwartungen werden auf menschliche Leistungen der Naturbeherrschung verlagert. Die Technizität wird mit einer Bedeutung versehen, die der religiösen Sphäre entstammt. ${ }^{40}$

Die Steigerung der technischen Beherrschbarkeit der Natur bzw. die gesellschaftliche Technisierung zwecks Erhöhung des Nutzens für den einzelnen Menschen führt zu einer parallelen Betrachtung der Ordnung des menschlichen Zusammenlebens unter dem Aspekt der "Machbarkeit“. ${ }^{41}$ Erstaunlich ist, dass gerade die Europäische Union durch eine Finalitätsverweigerung gekennzeichnet ist. ${ }^{42}$ Es scheint sich hier ein Verzicht auf die Ansprüche des säkularisierten Fortschrittsglauben und somit eine postmoderne Erscheinung der Modernisierung zu zeigen. Das Verweigern einer finalen, endgeschichtlichen politischen Zustandes ist Eschatologieverweigerung. Dies ist als Reaktion auf das Scheitern totalitärer Staaten zu deuten, deren totalitäre Fortschrittsideologie eine noch deutlichere Affinität zum heilsgeschichtlichen Erlösungsdenken besitzt.

Es schleicht sich zudem ein staatlicher verordneter Eudämonismus ein: der Staat wird zum Vollbringer irdischen Glücks. Auch auf anderer Ebene ist eine Verschiebung zu beobachten, eine Zunahme „privatwirtschaftlich geprägter Perfektionsansprüche“"43, die der Staat zu erfüllen hat.

Wenn der Staat zum Erlöser wird, dann wird er durch Verlagerungen der Religion in die Politik überfordert. Er wird damit beauftragt, das zu vollbringen, was früher die Religion leistete. ${ }^{44}$ Die Übertragung heilsgeschichtlicher Erwartungen auf den Staat ist ein Surrogat, das auf die Abschaffung des Verlustes der individuellen religiösen Dimension reagiert. Indiz für diese Verschiebungen ist beispielsweise das Anwachsen der positiven Verankerung von Staatszielen in Verfassungstexten, die die Möglichkeiten staatlicher Politik überfordern. ${ }^{45}$ Diese Prozess 
hat demokratiedefizitäre Auswirkungen, denn finale Normen mit ihren Zielbestimmungen erhöhen den Entscheidens- und Ermessensspielraum der exekutiven Organe.

Es wird zu einer politischen Aufgabe, was zuvor in der Händen der Religion lag. Der Staat wird nicht nur damit beauftragt, den Fortschritt voranzutreiben, sondern wird auch mit Kompetenzen auf der Ebene der individuellen Glückserfüllung ausgestattet, was zu einer notwendigen Beschneidung des Pluralismus von unterschiedlichen Glücksvorstellungen führt. ${ }^{46}$ Die Zunahme an Übertragung der Glücksverwirklichungskompetenz korrespondiert mit dem Wandel des klassischen liberalen Rechtsstaates, dessen negative Freiheitsrechte die Bürger vor dem Eingreifen des Staates schützten zu einem Staat, der zunehmend mit Ermächtigungsnormen ausgestattet ist und zu einem positiven Tun verpflichtet wird. Diese „Metamorphose der Rechtsnorm vom konditionalen zum finalen Programm" ${ }^{47}$ führt dazu, dass der Staat eine sinkende Steuerungsfähigkeit besitzt.

Der Staat wird allzuständig und ist Projektionsfläche für Leistungen, die durch die Religion nicht mehr erfüllt werden können. Das Projekt Moderne ist durch die Entmachtung der Religion und der Selbstlegitimierung neuzeitlicher Subjektivität gekennzeichnet. ${ }^{48}$ Dem Staat wird ein Maximum an Aufgaben und Aktivität überantwortet, die zu einem Anwachsen der Kluft zwischen empirischer Faktizität und normativem Ideal führt. Die Möglichkeit einer asymptotischen Annäherung an das angestrebte Ideal wird geringer. Das ist problematisch, weil der Fokus dadurch auf die Unvollständigkeit des Faktischen gerichtet ist, was zu einer Auswirkung auf Anreizstrukturen führen wird. Aus der Vergrösserung der Kluft folgt zudem eine Abnahme an Verwirklichungsmöglichkeit in der Faktizität des Politischen. Die wachsende Unmöglichkeit der Erfüllung der funktionalen Imperative führt notwendigerweise zu einem Vertrauensverlust in staatliche Politik und damit zu einer Er- schütterung des Fundamentes des modernen Rechtsstaates. ${ }^{49}$

\section{Braucht Europa Wunder?}

Der Glaube an Wunder ist Zeugnis eines Vertrauensverlustes in die Politik. Anlässlich der EU-Osterweiterung am 1. Mai 2004 hat sich der Schriftsteller Leon de Winter in einem Spiegel-Essay auf die Suche nach der europäischen Seele gemacht und ist zur Schlussfolgerung gelangt, dass die EU vielleicht jenes Wunder ist, dass mit der Kontinuität des Schreckens bricht: „Die Geschichte lehrt uns, dass grausame Konfrontationen mit Feinden immer und ewig auftreten. Vielleicht erleben wir derzeit ein Wunder, das damit bricht. Und vielleicht wird die EU als ein von anständigen Europäern bewerkstelligtes seelenloses Wunder dem Zahn der Zeit standhalten." 50 Der Glaube an Wunder zeugt von einem Vertrauensverlust in die Politik und einer Verantwortungsübertragung vom Menschen auf eine Instanz ausserhalb seines Einflussbereiches. Der Glaube an Wunder entlastet den Menschen: „Gemütlich ist aber eben das Wunder, weil es, wie gesagt, ohne Arbeit, ohne Anstrengung die Wünsche des Menschen befriedigt." ${ }^{1}$ Wer wünscht, entlastet sich selbst. Wer wünscht, misstraut dem Menschen als Herrn der Geschichte. Wer wünscht, dass die politische Gestaltung der Weltgeschichte sich zum Besseren wende, übernimmt einen theologischen Begriff und überträgt inn auf die irdische Politik. Die Politik kann aus der Hoffnung in eine bessere Zukunft kein Programm ableiten, aber wir benötigen Utopien, um unserer politischen Gegenwart einen gesellschaftskritischen Spiegel vorzuhalten und diese - jenseits des Religiösen und mit Blick auf ein politisches Ziel in der Zukunft - zu verändern. 


\section{Fussnoten}

1 Vgl. Lübbe, Hermann: „Ich entschuldige mich“. Das neue politische Bussritual, Berlin 2001. Vgl. auch der Essay über das politische Korrekte als Ritualisierung der Entschuldigung: Frenkel, Max: Äxgüsi, das ABC des politisch unkorrekten Schweizers, Zürich 2004.

2 Eine Analyse der Reden von Präsident George W. Bush zeigt, dass Gott nicht nur angerufen wird, um die USA zu schützen, sondern das politische Handeln der Regierung Bush durch seinen Namen legitimiert wird. Zudem zeigt sich, dass ein Vorsehungsmodell vorausgesetzt wird, dass die (Heils-)Geschichte Amerikas zu einem guten Ende bringen wird. Dadurch, dass Gott Amerikas positive Zukunft garantiert, wird die USA zum Vollbringer des göttlichen Willens. Damit eröffnet sich ein Freiraum politischen Handelns, der grenzenlos ist: „The momentum of freedom in our world is unmistakable - and it is not carried forward by our power alone. We can trust in that greater power who guides the unfolding of the years. And in all that is to come, we can know that His purposes are just and true. May God continue to bless America." (State of the Union Address von George W. Bush vom 20. Januar 2004; vgl. die Reden des Präsidenten auf: http://www.whitehouse.gov). Vgl. zu den transatlantischen Unterschieden den Beitrag von Gabriel N. Toggenburg in diesem Band. (bes. S. $34 \mathrm{ff}$ ).

${ }^{3}$ Vgl. Budelacci, Orlando: Gott, die Griechen und die EU-Verfassung; philosophische Reflexionen zur Verfassungpräambel. Erscheint im Band des Forschungskolloquiums Legitimationsgrundlagen der Europäischen Union" des Philosophischen Seminars der Universität Zürich. Vgl. auch: Ehrenzeller, Bernhard: „Im Bestreben, den Bund zu erneuern“. Einige Gedanken über "Gott“ und die „Welt" in der Präambel des „Bundesbeschlusses über eine neue Bundesverfassung“, in: (ders.) et ali. (Hrsg.): Der Verfassungsstaat vor neuen Herausforderungen. Festschrift für Yvo Hangartner, St-Gallen - Lachen SZ, 1998, S. 981-1000. Fleiner, Thomas: Die rechtliche und staatsphilosophische Bedeutung der Präambel unserer Bundesverfassung, in: Reformation, Jg. 25, 1976, S. 24-28. Gut, Walter: „Gott“ in der Bundesverfassung, in: Beiträge und Berichte des Instituts für Politikwissenschaft, Universität St. Gallen, 269/1998. Häberle, Peter: Präambeln im Text und Kontext von Verfassungen, in: Listl, Joseph/Schambeck, Herbert (Hrsg.): Demokratie in Anfechtung und Bewährung, Festschrift für Johannes Broermann, Berlin 1982, S.211-249. Hofmann, Hans: Das Grundgesetz ohne Gott - aber mit Mitmenschlichkeit, in: Zeitschrift für Rechtspolitik, Nr. 6, 1994, S. 215-219. Muschg, Adolf: Der Vorschlag für eine neue Präambel, in: Neue Zürcher Zeitung, Freitag 1. Juli 1977, Nr. 152, S. 33. Rich, Arthur: Theologische Erwägungen zur Präambel der Schweizerischen Bundesverfassung, in: Reformation, Jg. 25, 1976, S. 29-33. Saladin, Peter: Im Namen
Gottes des Allmächtigen, Erwägungen zur Präambel der Bundesverfassung, in: Reformation, Jg. 25, 1976, S. 15-23.

${ }^{4}$ In der Präambel des Entwurfs der EU-Verfassung heisst es: „Schöpfend aus den kulturellen, religiösen und humanistischen Überlieferungen Europas, deren Werte in seinem Erbe weiter lebendig sind und die zentrale Stellung des Menschen und die Vorstellung von der Unverletzlichkeit und Unveräusserlichkeit seiner Rechte sowie vom Vorrang des Rechts in der Gesellschaft verankert haben."

${ }^{5}$ Feuerbach, Ludwig: Das Wesen des Christentums, Frankfurt am Main 1994, S. 284.

${ }^{6}$ Marx, Karl: Zur Kritik der Hegelschen Rechtsphilosophie, Einleitung, in: Studienausgabe, Band 1, hrsg. von Iring Fetscher, Frankfurt am Main 1990, S. 21.

7 Nietzsche, Friedrich: Der Antichrist, in: Der Antichrist. KSA 6. Berlin - New York 1988, S. 183.

${ }^{8}$ Machiavelli: Discorsi, Stuttgart 1977, Kapitel 11-15, S. 47-56. Vgl. auch Münkler, Herfried: Machiavelli. Die Begründung des politischen Denkens der Neuzeit aus der Krise der Republik Florenz, Frankfurt am Main 1984, S.276 ff.

${ }^{9}$ Ottmann, Henning: Politik und Religion im modernen Staat, in: Leidhold, Wolfgang (Hrsg.): Formen und Probleme politischer Ordnung, Festgabe für Jürgen Gebhardt zum 65. Geburtstag, Würzburg 2000, S. 106.

${ }^{10}$ Dazu: Tugendhat, Ernst: Die ethische Gegenauflärung: Hegel und die Ritter-Schule; Alasdair Maclntyres After Virtue, in: (ders.): Vorlesungen über Ethik, Frankfurt am Main 1993, S. 197-225.

${ }^{11}$ Vgl. Walzer, Michael: Zweifel und Einmischung, Frankfurt am Main 1997.

12 Vgl. Ottmann, Henning: Philosophie und Politik bei Nietzsche, Berlin 1999.

${ }^{13}$ Vgl. Deleuze, Gilles: Nietzsche und die Philosophe, Hamburg 2002, S. $166 \mathrm{ff}$.

${ }^{14}$ Novalis: Die Christenheit oder Europa, in: Novalis. Werke und Briefe in einem Band, Zürich, S. 390. (ohne Jahresangabe.)

${ }^{15}$ Adorno, Theodor W und Horkheimer, Max: Dialektik der Aufklärung, Gesammelte Schriften, Band 5, S. 11-292.

${ }^{16}$ Arendt, Hannah: Elemente und Ursprünge totaler Herrschaft, Antisemitismus, Imperialismus, totale Herrschaft, München 1986, S. 978: „Was moderne Menschen so leicht in die totalitären Bewegungen jagt uns sie so gut vorbereitet für die totalitäre Herrschaft, ist die allenthalben zunehmende Verlassenheit."

17 Hegel: Phänomenologie des Geistes, Werke 3, Frankfurt am Main 1986, S. 433. ${ }^{18}$ Vgl. Taylor, Charles: Hegel, Frankfurt am Main 1978, S. 250 ff. Lyotard, JeanFrançois: Memorandum über Legitimität, in: Engelmann, Peter (Hrsg.): Postmoderne und Dekonstruktion, Frankfurt am Main 1999, S. 70.

${ }^{19}$ Hegel, Phänomenologie, a.a.O, S. 431.

${ }^{20}$ Marx fasst diesen Gedanken in folgende Worte: „Die Kritik der Religion enttäuscht 
den Menschen, damit er denke, handle, seine Wirklichkeit gestalte wie ein enttäuschter, zu Verstande gekommener Mensch, damit er sich um sich selbst und damit um seine wirkliche Sonne bewege." Marx, Zur Kritik der Hegelschen Rechtsphilosophie, a.a.O., S. 21.

${ }^{21}$ Kant, Immanuel: Kants Werke, Band XXIII, hrsg. von der Preussischen Akademie der Wissenschaften, Berlin 1902 ff., S. 347. (Akademieausgabe)

${ }^{22}$ Zur Dekonstruktion der zirkulären Identifikation von Ursprung und Ziel vgl. Derrida, Jacques: Schurken, Frankfurt am Main 2003, S. 21 ff. bes. S. $31 \mathrm{f}$.

${ }^{23} \mathrm{Vgl}$. Budelacci, Orlando: Kants Friedensprogramm. Das politische Denken im Kontext der praktischen Philosophie, Oberhausen 2003, S. $131 \mathrm{ff}$

${ }^{24}$ Tocqueville, Alexis de: Über die Demokratie in Amerika, Frankfurt am Main 1985, S.49.

25 Ottmann, Henning: Politische Theologie als Begriffsgeschichte. Oder: Wie man die politischen Begriffe der Neuzeit politisch-theologisch erklären kann, in: Gerhardt, Volker (Hrsg.): Der Begriff der Politik, Bedingungen und Gründe politischen Handelns, Stuttgart 1990, S. 169-188.

${ }^{26}$ Vgl. Schmitt, Carl: Politische Theologie, München 1922. Man lese etwa vor dem Hintergrund dieser Überlegungen die Ausführungen Hans Kelsens über die Souveränitätslehre: Kelsen, Hans: Souveränität, in: Klecatsky, Hans et ali. (Hrsg.): Die Wiener Rechtstheoretische Schule, Wien - Frankfurt - Zürich 1968, S. 164-178.

${ }^{27}$ Ottmann, Politische Theologie als Begriffsgeschichte, a.a.O., S. 187

${ }^{28}$ Schmitt, Carl: Das Zeitalter der Neutralisierungen und Entpolitisierungen, in: (ders.): Der Begriff des Politischen, Berlin 1996, S. 89.

${ }^{29}$ Ottmann, Politische Theologie als Begriffsgeschichte, a.a.O, S. 172.

${ }^{30} \mathrm{Vgl}$. Gusy, Christoph: Demokratiedefizite postnationaler Gemeinschaften unter Berücksichtigung der Europäischen Union, in: Brunkhorst, Hauke (Hrsg.): Globalisierung und Demokratie, Wirtschaft, Recht und Medien, Frankfurt am Main 2000, S. 131-150.

${ }^{31}$ Huntington, Samuel P.: Kampf der Kulturen, Die Neugestaltung der Weltpolitik im 21. Jahrhundert, München 1998, S. 146.

32 Op. cit. 144.

${ }^{33}$ Vgl. bspw. Barber, Benjamin: Coca-Cola und Heiliger Krieg. Wie Kapitalismus und Fundamentalismus Demokratie und Freiheit abschaffen, München 1996.

${ }^{34}$ Vgl. Derrida, Jacques: Die Religion, Frankfurt am Main 2001, S. 48.

${ }^{35}$ Op. cit. S. 49.

36 Op. cit. S. 48

${ }^{37}$ Op. cit. S. 48

${ }^{38}$ „Der glorreiche Sieg, welchen die aufklärerische Vernunft über das, was sie nach dem geringen Masse ihres religiösen Begreifens als Glauben sich entgegenge- setzt betrachtete, davongetragen hat, ist beim Lichte besehen kein anderer, als dass weder das Positive, mit dem sie sich zu kämpfen machte, Religion, noch dass sie, die gesiegt hat, Vernunft blieb und die Geburt, welche auf diesen Leichnamen triumphierend als das gemeinschaftliche, beide vereinigende Kind des Friedens schwebt, ebenso wenig von Vernunft als echtem Glauben an sich hat." Hegel: Glauben und Wissen oder Religionsphilosophie der Subjektivität in der Vollständigkeit ihrer Formen als Kantische, Jacobische und Fichtesche Philosophie, in: Werke 2, Jenaer Schriften 1801-1807, Frankfurt am Main 1970, S. 288.

${ }^{39} \mathrm{Vgl}$. Arendt, Elemente und Ursprünge totaler Herrschaft, a.a.O., S. 964

${ }^{40} \mathrm{Vgl}$. Schmitt, Das Zeitalter der Neutralisierungen und Entpolitisierungen, a.a.O., S. $84 \mathrm{f}$.

${ }^{41}$ Matz, Ulrich: Der überforderte Staat: Zur Problematik der heute wirksamen Staatszielvorstellungen, in: Hennis, Wilhelm (Hrsg.): Regierbarkeit: Studien zu ihrer Problematisierung, Stuttgart 1977, S. 82-102.

${ }^{42}$ Für Christian Meier ist das die EU auszeichnende integrative Moment die Tatsache, dass sie nicht bleiben kann, wie sie ist und dass nicht auszudenken ist, „was passiert, wenn sie am Ziel sein schiene." Meier, Christian: Welches Europa für welche Bürger?, in: Acham, Karl (Hrsg.): Europa - wohin? Zeitdiagnosen 1, Wien 2002, S. 21.

${ }^{43}$ Rhinow René: Aktuelle Herausforderungen der Demokratie, Schwindendes Systemvertrauen, in: Schweizer Monatshefte, Heft 12/01, Dezember/Januar 2002/ 2004, S. 17.

${ }^{44}$ Vgl. Honnefelder, Ludger: Gesellschaftliche Funktion und Eigenanspruch der Religion, in: Koslowski, Peter (Hrsg.): Die religiöse Dimension der Gesellschaft, Tübingen 1985, S. 288-291.

${ }^{45} \mathrm{Zu}$ den „Staatszielen“ vgl. die fundierte Studie von: Sommermann, Klaus-Peter: Staatsziele und Staatszielbestimmungen, Tübingen 1997.

${ }^{46}$ Vgl. Pieper, Annemarie: Glückssache. Die Kunst gut zu leben, Hamburg 2001 S.133-178.

${ }^{47}$ Hebeisen, Michael Walter: Staatszweck, Staatsziele, Staatsaufgaben, Leistungen und Grenzen einer juristischen Behandlung von Leitideen der Staatstätigkeit, Chur - Zürich 1996, S. 58.

${ }^{48}$ Gianni Vattimo vertritt hingegen die Ansicht, dass die Heilsgeschichte sich über den Umweg der Geschehnisse der Moderne ereignet. Dadurch führt er die Lehre Joachim des Fiores weiter, gemäss welcher die Krise eine Prüfungssituation ist Vgl. Vattimo, Gianni: Jenseits des Christentums. Gibt es eine Welt ohne Gott?, München 2004, bes. S. $59 \mathrm{ff}$

${ }^{49} \mathrm{Vgl}$. Ottmann, Henning: Verantwortung und Vertrauen als normative Prinzipien der Politik, in: Philosophie der Gegenwart - Gegenwart der Philosophie, Hamburg 1993 
S. 367-376. Saladin, Peter: Verantwortung als Staatsprinzip. Ein neuer Schlüssel zur Lehre vom modernen Rechtsstaat, Bern - Stuttgart 1984.

${ }^{50}$ De Winter, Leon: Wo steckt Europas Seele?, in: Der Spiegel, Nr.19, 3.5.2004, S

158.

51 Feuerbach, Wesen des Christentums, a.a.O., S. 212 f.

\section{Literaturverzeichnis}

Adorno, Theodor W. und Horkheimer, Max: Dialektik der Aufklärung, Gesammelte Schriften, Band 5, S. 11-292.

Arendt, Hannah: Elemente und Ursprünge totaler Herrschaft, Antisemitismus, Imperialismus, totale Herrschaft, München 1986.

Barber, Benjamin: Coca-Cola und Heiliger Krieg. Wie Kapitalismus und Fundamentalismus Demokratie und Freiheit abschaffen, München 1996.

Budelacci, Orlando: Gott, die Griechen und die EU-Verfassung; philosophische Reflexionen zur Verfassungpräambel. Erscheint im Sammelband des Forschungskolloquiums „Legitimationsgrundlagen der Europäischen Union“ des Philosophischen Seminars der Universität Zürich.

Budelacci, Orlando: Kants Friedensprogramm. Das politische Denken im Kontext der praktischen Philosophie, Oberhausen 2003.

De Winter, Leon: Wo steckt Europas Seele?, in: Der Spiegel, Nr.19, 3.5.2004, S. 152-158

Deleuze, Gilles: Nietzsche und die Philosophe, Hamburg 2002.

Derrida, Jacques: Die Religion, Frankfurt am Main 2001, S. 48.

Derrida, Jacques: Schurken, Frankfurt am Main 2003. 
Ehrenzeller, Bernhard: „Im Bestreben, den Bund zu erneuern“. Einige Gedanken über "Gott" und die „Welt" in der Präambel des „Bundesbeschlusses über eine neue Bundesverfassung“, in: (ders.) et ali. (Hrsg.): Der Verfassungsstaat vor neuen Herausforderungen. Festschrift für Yvo Hangartner, St-Gallen - Lachen SZ, 1998, S. 981-1000.

Fleiner, Thomas: Die rechtliche und staatsphilosophische Bedeutung der Präambel unserer Bundesverfassung, in: Reformation, Jg. 25, 1976, S. $24-28$.

Frenkel, Max: Äxgüsi, das ABC des politisch unkorrekten Schweizers, Zürich 2004.

Gusy, Christoph: Demokratiedefizite postnationaler Gemeinschaften unter Berücksichtigung der Europäischen Union, in: Brunkhorst, Hauke (Hrsg.): Globalisierung und Demokratie, Wirtschaft, Recht und Medien, Frankfurt am Main 2000, S. 131-150.

Gut, Walter: „Gott“ in der Bundesverfassung, in: Beiträge und Berichte des Instituts für Politikwissenschaft, Universität St. Gallen, 269/1998.

Häberle, Peter: Präambeln im Text und Kontext von Verfassungen, in: Listl, Joseph/Schambeck, Herbert (Hrsg.): Demokratie in Anfechtung und Bewährung, Festschrift für Johannes Broermann, Berlin 1982, S.211-249.

Hebeisen, Michael Walter: Staatszweck, Staatsziele, Staatsaufgaben, Leistungen und Grenzen einer juristischen

Behandlung von Leitideen der Staatstätigkeit, Chur - Zürich 1996.
Hegel: Glauben und Wissen oder Religionsphilosophie der Subjektivität in der Vollständigkeit ihrer Formen als Kantische, Jacobische und Fichtesche Philosophie, in: Werke 2, Jenaer Schriften 1801-1807, Frankfurt am Main 1970, S. 287-433.

Hegel: Phänomenologie des Geistes. Werke 3, Frankfurt am Main 1970.

Hofmann, Hans: Das Grundgesetz ohne Gott - aber mit Mitmenschlichkeit, in: Zeitschrift für Rechtspolitik, Nr. 6, 1994, S. 215-219.

Honnefelder, Ludger: Gesellschaftliche Funktion und Eigenanspruch der Religion, in: Koslowski, Peter (Hrsg.): Die religiöse Dimension der Gesellschaft, Tübingen 1985, S. 288-291.

Huntington, Samuel P.: Kampf der Kulturen, Die Neugestaltung der Weltpolitik im 1. Jahrhundert, München 1998.

Kant, Immanuel: Kants Werke, Band XXIII, hrsg. von der Preussischen Akademie der Wissenschaften, Berlin 1902 ff., S. 347. (Akademieausgabe)

Kelsen, Hans: Souveränität, in: Klecatsky, Hans et ali. (Hrsg.): Die Wiener Rechtstheoretische Schule, Wien - Frankfurt - Zürich 1968, S. 164-178.

Lübbe, Hermann: „Ich entschuldige mich“. Das neue politische Bussritual, Berlin 2001.

Lübbe, Hermann: Staat und Zivilreligion. Ein Aspekt politischer Legitimität, in: Achterberg, Norbert (Hrsg.): Legitimation des modernen Staates, Wiesbaden 1981, S. 40-64. 
Lyotard, Jean-François: Memorandum über Legitimität, in: Engelmann, Peter (Hrsg.): Postmoderne und Dekonstruktion, Frankfurt am Main 1999, S. 54-75.

\section{Machiavelli: Discorsi, Stuttgart 1977.}

Marx, Karl: Zur Kritik der Hegelschen Rechtsphilosophie, Einleitung, in: Studienausgabe, Band 1, hrsg. von Iring Fetscher, Frankfurt am Main 1990, S. 21-33.

Matz, Ulrich: Der überforderte Staat: Zur Problematik der heute wirksamen Staatszielvorstellungen, in: Hennis, Wilhelm (Hrsg.): Regierbarkeit: Studien zu ihrer Problematisierung, Stuttgart 1977, S. 82-102.

Meier, Christian: Welches Europa für welche Bürger?, in: Acham, Karl (Hrsg.): Europa - wohin? Zeitdiagnosen 1, Wien 2002, S. 19-35.

Münkler, Herfried: Machiavelli. Die Begründung des politischen Denkens der Neuzeit aus der Krise der Republik Florenz, Frankfurt am Main 1984.

Muschg, Adolf: Der Vorschlag für eine neue Präambel, in: Neue Zürcher Zeitung, Freitag 1. Juli 1977, Nr. 152, S. 33.

Nietzsche, Friedrich: Der Antichrist, in: Der Antichrist. KSA 6. Berlin New York 1988.

Novalis: Die Christenheit oder Europa, in: Novalis. Werke und Briefe in einem Band, Zürich, S. 389 - 408. (ohne Jahresangabe).

Ottmann, Henning: Philosophie und Politik bei Nietzsche, Berlin 1999.
Ottmann, Henning: Politik und Religion im modernen Staat, in: Leidhold, Wolfgang (Hrsg.): Formen und Probleme politischer Ordnung, Festgabe für Jürgen Gebhardt zum 65. Geburtstag, Würzburg 2000, S. $99-108$.

Ottmann, Henning: Politische Theologie als Begriffsgeschichte. Oder: Wie man die politischen Begriffe der Neuzeit politisch-theologisch erklären kann, in: Gerhardt, Volker (Hrsg.): Der Begriff der Politik, Bedingungen und Gründe politischen Handelns, Stuttgart 1990, S. 169-188.

Ottmann, Henning: Verantwortung und Vertrauen als normative Prinzipien der Politik, in: Philosophie der Gegenwart - Gegenwart der Philosophie, Hamburg 1993, S. 367-376.

Pieper, Annemarie: Glückssache. Die Kunst gut zu leben, Hamburg 2001.

Rhinow, René: Aktuelle Herausforderungen der Demokratie, Schwindendes Systemvertrauen, in: Schweizer Monatshefte, Heft 12/01, Dezember/Januar 2002/2004, S. 16-18.

Rich, Arthur: Theologische Erwägungen zur Präambel der Schweizerischen Bundesverfassung, in: Reformation, Jg. 25, 1976, S. 29-33.

Saladin, Peter: Im Namen Gottes des Allmächtigen, Erwägungen zur Präambel der Bundesverfassung, in: Reformation, Jg. 25, 1976, S. 1523.

Saladin, Peter: Verantwortung als Staatsprinzip. Ein neuer Schlüssel zur Lehre vom modernen Rechtsstaat, Bern - Stuttgart 1984. 
Schmitt, Carl: Das Zeitalter der Neutralisierungen und Entpolitisierungen, in: (ders.): Der Begriff des Politischen, Berlin 1996, S. 79-95.

Schmitt, Carl: Politische Theologie, München 1922.

Sommermann, Klaus-Peter: Staatsziele und Staatszielbestimmungen, Tübingen 1997.

Taylor, Charles: Hegel, Frankfurt am Main 1978.

Tocqueville, Alexis de: Über die Demokratie in Amerika, Frankfurt am Main 1985.

Tugendhat, Ernst: Die ethische Gegenauflärung: Hegel und die RitterSchule; Alasdair MacIntyres After Virtue, in: (ders.): Vorlesungen über Ethik, Frankfurt am Main 1993, S. 197-225.

Vattimo, Gianni: Jenseits des Christentums. Gibt es eine Welt ohne Gott?, München 2004.

Walzer, Michael: Zweifel und Einmischung, Frankfurt am Main 1997.
Gabriel N. Toggenburg

Der (dritte) Weg zur (v)erfassbaren Religionsidee der EU

\section{Neuer Europäischer Wertediskurs:}

\section{der politische Hintergrund}

In seiner Eröffnungsrede im Europäischen Konvent - jener illustren Versammlung, der 2002 und 2003 die historische Aufgabe zugekommen war, die zukünftige Verfassung der Europäischen Union zu entwerfen - forderte dessen Präsident Giscard d'Estaing Enthusiasmus für das Verfassungsprojekt ein und definierte diesen im besten griechischen Sinne, nämlich als „en-thousia“ mit der Bedeutung „von einem Gott inspiriert'. D' Estaing fügte allerdings geschwinde und einschränkend hinzu, dass es sich in diesem Falle um „die Inspiration durch eine Göttin, nämlich Europa" handle. Diese Einschränkung trübt jedoch nicht den festen Eindruck, dass Werte generell , und die Einstellung zu Gott im speziellen, im Rahmen der Debatte um den „Entwurf eines Vertrages über eine Verfassung für Europa" eine unerwartet präsente Rolle spielen.

Vor 15 Jahren hat man sich noch fragen können, ob sich das Europa zum fin-de siecle nicht bereits zum technokratischen Selbstzweck totgelaufen hat, und jeden tieferen raison d'etre verlustig geworden sein wird. ${ }^{1}$ Tatsächlich aber befindet sich der Prozess der Europäischen Integration nun knapp nach der Jahrtausendwende in einem recht umfassenden exercitium europeum der Selbst(wert)findung.

la. Verfassung, Grundrechte und politische Homogenität

Zumindest drei politische EU-Großereignisse haben dieses exercitium gleichzeitig mitbedingt wie veranschaulicht: Die Arbeiten an der Europäischen Grundrechtecharta, die Ende 2000 am Gipfel von Nizza verkündigt wurde; die so genannte Österreich Krise, die sich über 222 
Tage desselben Jahres hinzog und schließlich die Arbeiten an der EUVerfassung, die im Frühjahr 2002 begannen und Ende 2003 unter der italienischen EU-Präsidentschaft gescheitert sind und nun im Juni 2004 zum Abschluß der irischen EU-Präsidentschaft wieder zur Debatte stehen. Dieses Dreieck aus Grundrechtecharta, EU-Verfassung und Österreich Krise haben jeweils auf unterschiedliche Art und Weise und in jeweils unterschiedlicher Intensität einen Nachdenkprozess angeregt, der den Alltag des Europäischen Integrationsprozess unterbricht, die funktionalistische Methode der "Integration der Integration willen“ sistiert und die hilflose Ausflucht der EG (und später der EU) in die Figur eines "objet non identifie“, also eines unbekannten, primär wirtschafts-orientierten Integrationsobjektes mit undefinierten politischen Kurs, zunehmend kritisch hinterfragt.

Der Prozess des Konvents zur EU-Grundrechtecharta unter Präsidentschaft von Roman Herzog verursachte Fragen nach dem Sozial- und Politmodel Europas und suchte nach europäischen Antworten auf neue Herausforderungen etwa der Genetik oder der Informatik. Dennoch handelte es sich grösstenteils um eine legalistisch geprägte Kodifikation größtenteils schon bestehender Europäischen Grundrechte. Der mehr politisch geprägte Konventsprozess unter Giscard d'Estaing grub sich weit tiefer in Fragen der EU-Identität. Dem Verfassungskonvent zu Brüssel kamen die zwei geradezu historischen Aufgaben zu, das verworrene EU/EG Vertragsgeflecht zugänglicher, transparenter und schlüssiger zu gestalten und, zweitens, die Union strukturell an die Herausforderungen der Osterweiterung anzupassen. Dies brachte nicht nur zahllose technische Fragen, wie jener nach der EU-Kompetenzaufteilung oder der Typologie der Rechtsquellen, auf das Verhandlungstablett, sondern berührte auch Fragen der nationalen Identitäten, der Machtbalance zwischen der EU und ihren Staaten und wollte letztlich auch die Position der EU verschiedenen Werten gegenüber geklärt wissen. Darunter auch jene des Gottesbezuges der EU. Letzteres entpuppte sich gar als eine jener Kernfragen, denen umfassende Resonanz zukam. Noch politischer in seiner Natur war schließlich der Einfluss der Österreich-Krise. Im Rahmen dieses gleichermaßen unglücklichen wie glücklosen Versuches der EU-Mitgliedstaaten (minus Österreich), die Freiheitliche Partei Jörg Haiders aus der Koalition in Wien zu pressen, begann ein europaweites Nachdenken darüber, was denn nun eigentlich mit den „Europäischen Werte“ gemeint sei, die die angehende Koalitionsregierung in Österreich angeblich zu verletzen drohte. $^{2}$

Der Vertrag von Amsterdam hatte 1997 eine Werte-Klausel in das Vertragswerk aufgenommen. Art. 6 des EU-Vertrages listet die „Grundsätze der Freiheit, der Demokratie, der Achtung der Menschenrechte und Grundfreiheiten, sowie der Rechtsstaatlichkeiten" auf. Auf innen „beruht" die Union und diese Grundsätze „sind allen Mitgliedstaaten gemeinsam“. Werden diese Werte „schwerwiegend und anhaltend" verletzt, so kann die EU gemäss Art. $7 \mathrm{EU}$ den oder die Verletzerstaaten sanktionieren. Mit dieser Werteklausel wendete die EU 1997 jenes Wertekorsett nach innen, welches sie vorher, in den Schlussfolgerungen des Europäischen Rates von Kopenhagen 1993, den Kandidatenstaaten als Beitrittsbedingungen vorgeschrieben hatte. ${ }^{3}$ Die Tatsache, dass bei dieser „Invertierung“ der Werte eines der politischen Kriterien von Kopenhagen aussen vor gelassen wurde, nämlich der Respekt gegenüber und der Schutz von (auch religiösen) Minderheiten wie auch die Erfahrung der Österreich-Krise zeigten, ${ }^{4}$ dass die Wertedebatte entlang der (mitunter dünnen) Grenze zwischen Recht und Politik geführt wird.

Während der Impuls dieser drei genannten Faktoren mittlerweile am verblassen ist, gewinnt ein vierter Faktor in der Wertedebatte an Bedeutung. Ein Faktor, der zwar bereits mehr als ein Jahrzehnt latent vorhanden ist, aber erst jetzt, im Laufe des Jahres 2004 virulent wird: 
die Fragen rundum den Beitritt der Türkei und die Rolle des Islams in Europa.

\section{I.b. Der Islam und die islamischen Staaten im Dreieck zwischen Ankara, New York und Brüssel}

Gegen Herbst 2004 wird die Kommission darüber befinden, ob mit der Türkei, Beitrittsverhandlungen zu eröffnen seien. Ein diesbezüglich positiver Avis der Kommission würde politisch als ein Ja zu einem EUBeitritt der Türkei gewertet werden. Eine prinzipielle Beitrittsfähigkeit der Türkei ergibt sich allerdings bereits aus den Ausführungen des Europäischen Rates von Helsinki, der im Dezember 1999 die Türkei als ein „ein beitrittswilliges Land, das auf der Grundlage derselben Kriterien, die auch für die übrigen beitrittswilligen Länder gelten, Mitglied der Union werden sol/" bezeichnete und damit die Türkei als Beitrittskandidat anerkannt hat. ${ }^{5}$ Politisch hat sich die Europäische Gemeinschaft gar bereits im Assozierungsvertrag von 1963 gebunden, da es dort in der Präambel heißt, dass die wirtschaftliche Kooperation, „später den Beitritt der Türkei zur Gemeinschaft erleichtern wird“. ${ }^{6}$ Es ist somit zu spät, um den Beitrittszug, der seit 1963 von Ankara in Richtung Brüssel unterwegs ist aus prinzipiellen Gründen aufzuhalten. Alles deutet darauf hin, dass die EU die Türkei bereits als „Europäischer Staat“ im Sinne des Art. 49 EU anerkannt hat - als ein Staat also, der im Prinzip EU Mitglied werden kann. ${ }^{7}$ Dies deckt sich im übrigen mit der Behandlung der Türkei im Rahmen des Europarates. ${ }^{8}$ Es kann allerdings bezweifelt werden, ob diese weitreichende Entscheidung der Europäischen Eliten auch am soziokulturellen Boden der nunmehr $25 \mathrm{EU}-\mathrm{Ge}-$ sellschaften ausreichend nachvollzogen wurde. Vielmehr ist davon auszugehen, dass es gerade im Umfeld der Europawahlen 2004 und danach, zu einer öffentlichen Nachkontrolle dieser bereits getroffenen Kulturentscheidung kommen wird. Dies umso mehr, als die prinzipiellen Argumente gegen eine Beitrittsmöglichkeit sich lange (und erfolg- reich) hinter dem Argument einer mittelfristig auszuschließenden Beitrittsfähigkeit der Türkei verstecken konnten. Das hat sich geändert. Nach einschneidenden Verfassungsreformen in der Türkei, die von der Europäischen Kommission lobend anerkannt wurden, wird das argumentative Eis für eine Ablehnung der Türkei wegen Nichteinhaltung der Kopenhagen Kriterien immer dünner. ${ }^{9}$ Die Skeptiker werden somit aller Voraussicht nach wieder vermehrt auf die prinzipiellen, sprich kulturellen Argumente gegen einen Beitritt der Türkei rekurrieren und darauf setzen, dass - juristisch gesehen - der Rat nicht gezwungen ist, die Verhandlungen zu eröffnen. Selbst wenn der Rat, auf der Grundlage eines positiven Beschlusses der Kommission, die Eröffnung der Verhandlungen beschließt, präjudizierte er damit nicht den eigentlichen, mit Einstimmigkeit zu fällenden Aufnahmebeschluss des Rates, der nur nach Zustimmung des Europäischen Parlaments gefällt werden kann (Art. $49 \mathrm{EU})$

Es wird sich zeigen, wie sich diese verspätete, umfassende Debatte gestalten wird. Fest steht jedenfalls, dass die Religion, die Stellung des Staates zur Religion und der Islam an sich eine wesentliche Rolle spielen werden. Schließlich würden die über 68 Millionen Bürger, die zu nahezu $100 \%$ muslimischen Glaubens sind, den kulturell-religiösen Mix der EU wesentlich ändern. Dies umsomehr als die Türkei aufgrund ihres hohen Bevölkerungswachstums sehr schnell größter EU-Mitgliedstaat sein würde. ${ }^{10}$

Diese Perspektive rückt das Augenmerk auf den Islam wie er bereits jetzt in der EU 25 präsent ist. Europa, insbesondere die iberische Halbinsel, ist, historisch gesehen, kulturell von der islamischen Kulturwelt mitgeprägt. Einige Mitgliedstaaten wie England, Deutschland, Frankreich, Niederlande und Belgien die zusammen bereits Heim für über 11 Millionen Moslems sind, stehen vor ganz konkreten Herausforderungen des multikulturellem Zusammenlebens. ${ }^{11}$ Insbesondere die 
Kopftuchdebatte in Deutschland und Frankreich zeigt, dass multikulturelle Einflüsse zu einem neuen Prozess der Selbstdefinition zwingen. ${ }^{12}$ Unter kulturrelevanten Regelungen der Mehrheitskultur sind auch Regelungen, die bloß nebenher als „kultureller Schatten“ der letzteren entstehen und nun hinterfragt werden. ${ }^{13}$ Auf juristischer Ebene ist der Islam bereits Bestandteil Europäischer Rechtsanwendung. Über das Zivilrecht, vor allem das Internationale Privatrecht (IPR) fließt islamisches Recht in Europäische Rechtsordnungen und kommt dort vor den Gerichten als eine Art "Gastrecht“ zur Anwendung. Soweit das jeweilige IPR an die Staatsangehörigkeit anknüpft, ist etwa vor deutschen oder französischen Gerichten islamisches Familien- oder Erbrecht anzuwenden. So ist in Deutschland bereits die islamische talaq - das einseitige Recht des Mannes auf Scheidung - zur Anwendung gekommen. Allerdings gelten gewisse (verfassungs)rechtliche Grenzen. ${ }^{14} \mathrm{Es}$ kommt somit zu einem Normenab- und ausgleich. Ein solcher Systemdiskurs, der zu einer europäisierten Version des Islam führen könnte, ist Ziel und Hoffnung vieler. Unter dem von Bassam Tibi geprägtem Schlagwort des „Euro-Islam" sucht man nach dem islamischen Antlitz Europas und dem europäischen Antlitz des Islams. Vor dem Hintergrund des 11. September 2001 bekommt dieser Wertediskurs eine ungeahnt weitreichende, ja geradezu globale Dimension und scheint Europa nolens volens mit einer neuen Verantwortung zu betrauen.

Die vom Weißen Haus ausgehende Polarisierung zwischen „bad“ and "good" und konkludent zwischen "West" und "Non-West" ließ in Europa die Frage laut werden, was denn nun heute noch unter „westlich“ gemeint sein könnte und welchen Werten zum einen der undefinierte „Westen“ zum anderen aber insbesondere Europa selbst verpflichtet sei. Es wurde darüber nachgedacht, ob sich die Werte der machtorientierten Amerikaner wesentlich und prinzipiell von jene der mehr toleranzgeprägten Europäern unterscheiden würden. ${ }^{15}$ Die Krise des Westens und damit auch der transatlantischen Partnerschaft war (und ist) auch eine Krise der Werte. ${ }^{16}$ Der Versuch, die Ära nach 11.09. so gut wie möglich von der Optik eines Kulturkampfes und der Aussicht auf einen bis dato eher belächelten "Clash of civilisations" fernzuhalten gelingt nur mühsam. Diplomatische Querschläger wie die Erklärung von Berlusconi, ${ }^{17}$ damals designierter EU-Präsident, zum Herrschaftsanspruch der westlichen Kultur, der sich zuspitzende Nahost Konflikt und schließlich katastrophale Fehlentwicklungen im Irak wie die jüngsten Foltervorwürfe gegen die Vereinigten Staaten schütten Treibstoff auf einen glimmenden „Kulturkampf“, der in seinen Anfängen erstickt werden muss.

Europa kommt angesichts dieser drohenden Sollbruchstelle eine wachsende Verantwortung zu. Diese wird in Brüssel auch geortet. Man versucht die bereits 1995 in Barcelona lancierte Partnerschaft EuropaMittelmeer als ein Forum für den Dialog auch zwischen den Kulturen zu nutzen. Es bleibt abzuwarten, ob die nahe Zukunft eine wesentliche Verstärkung dieser Ansätze bringen wird. Dies insbesondere in finanzieller Hinsicht. Schliesslich nähren sich die klar ersichtlichen Spannungen nicht primär aus der Religion.Die Europäische Kommission erkennt an, dass es auch ganz wesentlich um globale politische Ungerechtigkeit und die vorherrschende Frustrationsperzeption geht, dass man als Mensch im arabischen Raum ohnmächtiger Globalisierungsverlierer sei. „Angesichts dieser und anderer Konfliktsituationen muss Europa seine gesamten politischen und wirtschaftlichen Möglichkeiten aufbieten und Kreativität beweisen, um einen Raum des Dialogs zu schaffen“, führt Prodi hierzu aus. ${ }^{18}$ Europa als wirtschaftlich fördernder und politisch mahnender Vermittler also.

Einen ersten groß angelegten Politikansatz dazu mag man in der neuen, erst Mitte März 2004 lancierten, und Mitte Mai 2004 mit einem Strategiepapier und verschiedenen Länderberichten ausgefüllten „Europäischen Nachbarschaftspolitik“, erkennen. ${ }^{19}$ Die „Vision“ der ENP definiert die 
Kommission folgendermaßen: „ein Ring aus Ländern, die die grundlegenden Werte und Ziele der EU teilen und in eine zunehmend engere Beziehung eingebunden werden, die über die Zusammenarbeit hinaus ein erhebliches Maß an wirtschaftlicher und politischer Integration beinhaltet. Das wird allen Beteiligten in Bezug auf Stabilität, Sicherheit und Wohlstand enorme Vorteile bringen“. Beruhen soll diese „privilegierte Nachbarschaft" auf eine gegenseitige Verpflichtung auf gemeinsame Werte. Dies sind die klassischen Werte des Art. 6 EU aber auch jene Werte, die schon im Rahmen der Heranführung der neuen Mitgliedstaaten unterstrichen wurden, wie der Schutz von Minderheiten oder Kindern. Ferner wird ein „engagement für bestimmte wesentliche Aspekte des externen Handelns der EU angestrebt, darunter insbesondere die Bekämpfung des Terrorismus". Das bewährte Zuckerbrot und Peitsche Prinzip kommt elegant formuliert aber klar zum Ausdruck: „Die EU wird in ihrem Ergeiz beim Ausbau der Verbindungen zu jedem Partnerland durch die ENP berücksichtigen, inwiefern die gemeinsamen Werte tatsächlich geteilt werden“. Eines der vier wesentlichen Elemente der ENP soll die Förderung grenzüberschreitender Kontakte zwischen den Bevölkerungen sein (,people-to-people“). Damit werden Bürger der Union und ihrer Nachbarn zusammengebracht, um „das gegenseitige Verständnis für die Kultur, Einstellungen und Werte des anderen auszubauen und verzerrte Wahrnehmungen auszumerzen".

Die Kommission schlägt vor die ENP „in Europa“ für Russland, die Ukraine und Moldau zu öffnen. In der Mittelmeerregion soll die ENP für alle Teilnehmer des Barcelona Prozesses gelten mit Ausnahme der Türkei (die ihre Beziehungen im Rahmen der Heranführungspolitik unterhält) also für Algerien, Ägypten, Israel, Jordanien, Libanon, Marokko, Syrien, Tunesien sowie die Palästinensische Behörde. Die ENP ist variabel und wird für jeden Staat ein anderes Gesicht haben. In „Aktionsplänen“ werden die Prioritäten der jeweiligen Beziehung festgelegt. Die
Kommission empfiehlt, dass jeder Beschluss über die (Weiter)entwicklung der jeweiligen vertraglichen Beziehung erst auf der Grundlage eines Kommissionsberichts erfolgen wird. Das erweiterungserprobte, jährliche „monitoring“ der Kommission lebt gegenüber den neuen Nachbarn im Osten und den alten, aber strategisch nun eminent wichtigen Partnern im Süden wieder auf.

Inwieweit es Europa gelingen wird die islamischen Staaten aus einer falschen, aber doch drohenden Dichotomie "Islam oder Westen" herauszuhalten wird auch wesentlich davon abhängen, ob es gelingen wird, die Türkei fest und dauerhaft an die politische Zone EU-Europas anzukoppeln - ob nun im Rahmen einer Vollmitgliedschaft oder einer vergleichbar dichten Integration. Die Türkei mag man insofern gerne als neuralgisches Scharnier zwischen „dem" (real vielleicht gar nicht mehr existierendem) „Westen“ und „dem“ (wohl gar nie einheitlich bestandenen) Islam sehen ${ }^{20}$.

\section{I.c. Gott und Verfassung: transatlantische Unterschiede, europäische Unsicherheiten}

Wie "gottesnah" darf das offizielle Europa aber sein, wenn es glaubhaft zwischen der empfindlich gläubigen islamischen Welt und der inbrünstigen aber doch mitunter unempfindsamen „Beseeltheit“ Amerikas vermitteln soll? Man mag sich in diesen Zusammenhang an die unglückliche Idee des Weißen Hauses erinnern, die Vergeltungsoperation nach dem 11 September unter dem Schlachtruf "Infinite Justice" zu stellen. Erst als moslemische Gruppen erbost anmerkten, dass nur Allah ewige Gerechtigkeit herstellen könne, wurde dieser Faux Pass bereinigt und die islamischen Koalitionspartner beruhigt.

Das offizielle Amerika hat generell weit weniger Berührungsängste gegenüber der Religion als das offizielle Europa. In den Vereinigten Staa- 
ten ist Gott Verfassungsrealität. Zwar schweigt sich die Präambel der US Verfassung zu Gott aus, doch bereits seit George Washington fügen die amerikanischen Präsidenten bei der Einschwörung vier von der Verfassung eigentlich nicht vorgesehene Wörter zum dort vorgeschriebenen Schwur hinzu: „So help me God". ${ }^{21}$ Das amerikanische Wappen enthält das Dreieck samt (Gottes) Auge und den Spruch „annuit Coeptis" (Er, der unsere Geschicke förderte). Das ursprüngliche nationale Motto „E pluribus unum" verlor neben dem Motto "In God we trust", welches erst 1956 eingeführt wurde, an Bedeutung. ${ }^{22}$ Bereits 90 Jahre vorher war das "In God we trust" für das Münzgeld vorgeschrieben worden. ${ }^{23}$ Ab 1966 wurde dieses Motto auch Teil des amerikanischen Papiergeldes. Es wird argumentiert, dass die religiöse Erneuerung des nationalen Motto sowie die Ergänzung des Fahneneides mit den Worten „under god" - beides in den fünfziger Jahren vorgenommen - mit der heißen Phase des Kalten Krieges zusammenhänge und damals der demonstrativen Abgrenzung vom - als atheistisch apostrophierten - Kommunismus diente. ${ }^{24}$

Beides, Eid wie Motto, wurden zwar mehrmals Gegenstand verfassungsrechtlicher Zweifel vor verschiedenen US-Gerichten. Aber in aller Regel befindet das amerikanische Rechtsystem diese Nähebekundigungen zu Gott als unproblematisch, so auch der US Supreme Court. ${ }^{25}$ In Aronow v. United States befand etwa ein Federal Court, dass es "quite obvious" sei, dass "the national motto and the slogan on coinage and currency "In God We Trust" has nothing whatsoever to do with the establishment of religion. Its use is of patriotic or ceremonial character and bears no true resemblance to a governmental sponsorship of a religious exercise ". ${ }^{26}$ Erst kürzlich war das Aufsagen des "gottesträchtigen" Eides in der Schule ein Thema vor Gerichten. Im Juni 2002 erklärte ein Federal Court den Eid als für mit dem Verfassungsrecht, nämlich der so genannten Establishment Clause im First Amendment, unvereinbar. ${ }^{27}$ Diese besagt, dass, „the
Congress shall make no law respecting an establishment of religion". Unverzüglich unterstützten Senat wie Repräsentantenhaus den entsprechenden Passus im Eid - mit jeweils überwältigenden Mehrheiten. Gegen die Entscheidung wurde berufen, aber das Gericht lehnte eine abermalige Behandlung im Plenum ab. Bush soll das Urteil als „lächerlich" kommentiert haben und der Vorsitzender des Justizausschusses im Repräsentantenhaus problematisierte, dass das Gericht sich gerade in einer Zeit verweigere, in der sich die Nation auf einen „impending war to defend the values upon which our great nation is founded" vorbereite. ${ }^{28}$

Die Lage auf der anderen Seite des Atlantiks ist diesbezüglich kontrastierend - in Europa zeigt man sich viel zurückhaltender in Sachen Religion und Kirche. Manche meinen (mitunter mit Häme), dass dies nur den Niedergang der Stellung der Religion in den EU-Staaten wiederspiegle. ${ }^{29}$ Andere meinen, dass der Moment der Verfassungsgebung Anlaß genug sei, sich des religiösen Erbes Europas zu entsinnen. J.H.H. Weiler unterstreicht gar, dass nicht die Bezugnahme auf das Christentum, sondern dessen Unterlassen argumentationsbedürftig sei. In seinem jüngst erschienen „Un'Europa cristiana“ meint er, dass das Schweigen der EU-Verfassung zum Christentum ein Akt der Selbstverleugnung Europas, ja gar der "Christophobie" sei. ${ }^{30}$ Schließlich hört man mitunter beschwichtigend von Befürwortern eines Gottesbezuges, dass dieser nicht Bekenntnischarakter habe, sondern vielmehr eine Quelle aufzeige, aus der "die Bereitschaft zur Übernahme von Verantwortung gespeist wird". ${ }^{31}$ Der Gottesbezug tangiere deshalb weder die Trennung von Kirche und Staat, noch sei er für Angehörige einer bestimmten Religion unzumutbar. Der Gottesbezug diene demnach dem "friedliche[n] und gerechte[n] Zusammenleben der Menschen“" ${ }^{32}$ Es lässt sich an ein langfristig angelegtes Verantwortunsgefühl für die Schöpfung (also für die Erde in profaneren Augen) allerdings auch ohne transzendentale Ankoppelung im Verfassungstext appellieren, weshalb 
im Sinne eines Kompromisses - mit Erfolg - vorgeschlagen wurde, in der Verfassungspräambel auf die Verantwortung gegenüber künftigen Generationen zu verweisen. ${ }^{33}$ Die Ansätze angesichts der Arbeiten an der EU-Verfassung divergierten somit wesentlich. Und entsprechend bescheiden fiel die transzendentale Anbindung des Verfassungsvertrages auch aus. Weder auf Gott noch auf das Christentum wird im aktuellen Entwurf des Verfassungsvertrages Bezug genommen. Wohl zur Genugtuung der Türkei, die sich gegen einen Gottesbezug eingesetzt hatte, den sie als STOP-Schild in Richtung Türkei und anderen potentiellen, islamisch geprägten Beitrittskandidaten versteht. Die Debatte ist allerdings noch nicht ausgestanden. Kurz vor Beginn der aktuellen Regierungskonferenz im Juni 2004, die endgültig die EU-Verfassung aus der Taufe heben soll, haben 7 EU-Mitgliedstaaten (Italien, Litauen, Malta, Polen, Portugal, Slowakei, Tschechische Republik) einen Brief an die irische EU-Präsidentschaft gesendet, in dem sie sich für einen Bezug auf das Christentum in der EU-Verfassung aussprechen.

Im Folgenden sollen die religionsrelevanten Teile des zur Diskussion stehenden Konventsentwurfes für einen EU-Verfassungsvertrag vorgestellt werden (Teil II). Dann wird diskutiert, ob es ein EU-Religionsrecht gibt (Teil III) und schließlich untersucht, inwieweit die Europäische Union eine Religionsidee hat (Teil IV). In einem letzten Teil soll aufgezeigt werden, wie ein juristisch schlüssiger Gottesbezug doch noch auf politischen Konsens treffen könnte (Teil V).

\section{Religion im Verfassungsvertrag: bits and pieces}

Religion findet sich expressis verbis an fünf Orten bzw. in fünf Zusammenhängen im vom Europäischen Konvent 2003 vorgeschlagenen "Entwurf eines Vertrages über eine Verfassung für Europa“34: den Präambeln ${ }^{35}$; der Bestimmung zum Verhältnis zwischen der EU und den
Kirchengemeinschaften; den Grundrechten (Recht auf Bildung sowie der Gedanken-, Gewissens- und Religionsfreiheit); dem Diskriminierungsschutz (als Verbots -wie Politiknorm) sowie den Vielfaltsklauseln. Die meisten der Bezugnahmen sind nicht wirklich neu.

\section{II.a. Die Präambel}

Juristisch am bedeutungslosesten aber politisch am weitaus brisantesten ist hierbei die Präambel am Eingang des Verfassungsvertrages. ${ }^{36}$ Während die Präambel zur Grundrechtecharta als Teil der Grundrechtecharta ausser Streit gestellt und direkt in den Teil II des Verfassungsvertrages überstellt wurde, mauserte sich die Frage zum Gottesbezug in der Vertragspräambel selbst zu einem der wenigen wirklichen Knackpunkte im Rahmen der Verfassungsdebatte im Vorfeld der Regierungskonferenz 2003. Im Unterschied zu diesem für manchen vielleicht geradezu exotisch anmutenden Streitpunkt, waren all die anderen „hot issues" machtpolitisch äußerst relevante und altbekannte Agenden des gemeinschaftsrechtlichen „institutional engineering “ wie etwa die Zusammensetzung der Europäischen Kommission, die Rolle des neuen Europäischen Präsidenten oder der Frage an der letztlich die Regierungskonferenz kläglich scheiterte, nämlich die Stimmgestaltung im Rat der EU. Jenes Land, dessen Unnachgiebigkeit in dieser letzten Frage das Verfassungsprojekt scheitern ließ, war auch aktiver Verfechter eines Gottesbezuges im Verfassungsvertrag. Polen hatte sich bereits im Rahmen des Konvents für einen entsprechenden Passus in der Verfassungspräambel eingesetzt, war damit aber gescheitert. Die derzeit vorliegende Präambel des Verfassungsvertrags schöpft zwar aus den „kulturellen, religiösen und humanistischen Überlieferungen Europas", aber erwähnt weder Gott noch das Christentum ausdrücklich. Sie liest sich wie folgt: 
„In dem Bewusstsein, dass der Kontinent Europa ein Träger der Zivilisation ist und dass seine Bewohner, die ihn seit Urzeiten in immer neuen Schüben besiedelt haben, im Laufe der Jahrhunderte die Werte entwickelt haben, die den Humanismus begründen: Gleichheit der Menschen, Freiheit, Geltung der Vernunft,

Schöpfend aus den kulturellen, religiösen und humanistischen Überlieferungen Europas, deren Werte in seinem Erbe weiter lebendig sind und die zentrale Stellung des Menschen und die Unverletzlichkeit und Unveräußerlichkeit seiner Rechte sowie den Vorrang des Rechts in der Gesellschaft verankert haben,

In der Überzeugung, dass ein nunmehr geeintes Europa auf diesem Weg der Zivilisation, des Fortschritts und des Wohlstands zum Wohl all seiner Bewohner, auch der Schwächsten und der Ärmsten, weiter voranschreiten will,dass es ein Kontinent bleiben will, der offen ist für Kultur, Wissen und sozialen Fortschritt, dass es Demokratie und Transparenz als Wesenszüge seines öffentlichen Lebens stärken und auf Frieden, Gerechtigkeit und Solidarität in der Welt hinwirken will,

In der Gewissheit, dass die Völker Europas, wiewohl stolz auf ihre nationale Identität undGeschichte, entschlossen sind, die alten Trennungen zu überwinden und immer enger vereint ihr Schicksal gemeinsam zu gestalten,

In der Gewissheit, dass Europa, „in Vielfalt geeint“, innen die besten Möglichkeiten bietet, unter Wahrung der Rechte des Einzelnen und im Bewusstsein ihrer Verantwortung gegenüber den künftigen Generationen und der Erde dieses große Abenteuer fortzusetzen, das einen Raum eröffnet, in dem sich die Hoffnung der Menschen entfalten kann,

In dankender Anerkennung der Leistung der Mitglieder des Europäischen Konvents, die diese Verfassung im Namen der Bürgerinnen und Bürger und der Staaten Europas ausgearbeitet haben..."

(Hervorhebungen durch den Autor)
Dennoch ist die Bezugnahme auf „religiöse Überlieferungen“ stärker ausgefallen als dies noch bei der Präambel zur Grundrechtecharter der Fall war. Dort nämlich fand und findet sich trotz vehementen Gerangels um diesen passus nur eine Bezugnahme auf das „spiritualmoral heritage“, „patrimoine spirituel et moral" oder ",patrimonio spirituale e morale". Für einen religionsnaheren Bezug hatte im HerzogKonvent noch eine politische Mehrheit gefehlt. Beachtenswert ist jedoch, dass diese vorsichtige Formulierung des ersten Konvents im Deutschen nur sehr unglücklich mit "geistig-moralisch“ zu übersetzen gewesen wäre und somit in seiner deutschen Version - ganz zu Freuden der christdemokratischen Abgeordneten - in das stärkere "geistigreligiöse" kippte. So heißt es nun in der Präambel zum Teil II des Verfassungsvertrages (Charta der Grundrechte):

„Die Völker Europas sind entschlossen, auf der Grundlage gemeinsamer Werte eine friedliche Zukunft zu teilen, indem sie sich zu einer immer engeren Union verbinden.

In dem Bewusstsein ihres geistig-religiösen und sittlichen Erbes gründet sich die Union auf die unteilbaren und universellen Werte der Würde des Menschen, der Freiheit, der Gleichheit und der Solidarität. ...

Die Ausübung dieser Rechte ist mit Verantwortlichkeiten und Pflichten sowohl gegenüber den Mitmenschen als auch gegenüber der menschlichen Gemeinschaft und den künftigen Generationen verbunden. Daher erkennt die Union die nachstehend aufgeführten Rechte, Freiheiten und Grundsätze an."

(Hervorhebungen durch den Autor).

Die dem Verfassungsvertrag selbst vorangestellte Präambel stellt (insbesondere zu den nicht-deutschen Versionen der Präambel zur Grundrechtecharta) eine Verdeutlichung des religiösen Erbes Europas dar, bleibt aber gleichzeitig weit hinter all den Erwartungen all jener 
zurück, die eine Bezugnahme auf Gott oder das Christentum gefordert hatten.

Die verschiedenen Ansätze zur Verstärkung der religiösen Dimension in der Präambel des Verfassungsvertrages reichten von der Einfügung des Gottesglaubens bzw. des Christentums als Beispiel für das religiöse Erbe $^{37}$ über eine Ergänzung des kulturellen und humanistischen Erbes durch das „christlich-jüdische Erbe“"38, bis zur (zusätzlichen) Verankerung des notwendigen Respekts vis a vis der "freedom of conscience and belief in God"39. Eine Kombination der letzten beiden Elemente findet sich etwa im Änderungsvorschlag der EPP Gruppe im Konvent. ${ }^{40}$ Auch die Kirchen - und in aller Deutlichkeit auch der Papst hatten sich aktiv in den diesbezüglichen Diskussionsprozess eingebracht. ${ }^{41}$ Hiezu verwendeten sie die bereits in der Erklärung von Laeken angekündigte Forum-website der $\mathrm{EU}^{42} \mathrm{bzw}$. beteiligten sich an der Anhörung der Zivilgesellschaft. ${ }^{43}$ Wie auch bereits im Zusammenhang mit dem ersten Konvent (jener der die Grundrechtecharta entworfen hatte) waren die Kirchen relativ vorsichtig und setzen nicht auf die Verankerung des Terminus "Gott" ${ }^{44}$ in der Verfassung, sondern konzentrieren sich auf die Bezugnahme auf das religiöse Erbe Europas und zum anderen auf die Absicherung der Autonomie der gesetzlichen Situation der Kirchen in den Mitgliedstaaten. Die scharf laizistisch geprägte Tradition Frankreichs wie auch der herannahende EU-Beitritt der Türkei mobilisierten beträchtliches Widerstandspotential gegen weitergehende Vorschläge. Äußerungen wie insbesondere jene von Giscard d'Estaing im November 2003 bzgl. eines Beitritts der Türkei waren für viele Anlaß, eine gefährliche Tendenz zu erkennen, Europa als geschlossenen christlichen Club zu etablieren. ${ }^{45}$ Gleiches Schicksal ereilte umso mehr all jene Versuche, einen religiösen Bezug in den Wertekalog des Art. I-8 des Verfassungsvertrages zu verankern. Selbst die als vorbildlich gehandelte, ${ }^{46}$ weil inklusiv-tolerante Formulierung der polnischen Verfassung (dazu noch kritisch weiter unten), dem sich die
EPP Abgeordneten ${ }^{47}$ wie auch andere angenommen hatten, war nicht konsensfähig. Der folgende, von mehr als zwei Dutzend Konventsmitgliedern unterstützte Antrag, den folgenden passus „an geeigneter Stelle" in die künftige Verfassung zu integrieren, scheiterte:

„Die Werte der Europäischen Union umfassen die Wertvorstellungen derjenigen, die an Gott als die Quelle der Wahrheit, Gerechtigkeit, des Guten und des Schönen glauben, als auch derjenigen, die diesen Glauben nicht teilen, sondern diese universellen Werte aus anderen Quellen ableiten" " ${ }^{8}$

\section{II.b. Die Kirchenklausel}

Kommen wir aber zu der weniger öffentlichkeitswirksamen, juristisch aber bedeutungsvolleren Bestimmung im Teil I des Verfassungsvertrages. Dieser erste Teil des Verfassungsvertrages enthält vornehmlich - ohne dies in einem Titel selbst festzuschreiben - die wesentliche Verfassungsstruktur der EU. ${ }^{49}$ Im Titel VI „Das demokratische Leben der Union" findet sich nach Artikeln zum Grundsatz der demokratischen Gleichheit, der repräsentativen und direkten Demokratie, den Sozialpartnern, den Bürgerbeauftragten, der Transparenz der Unionsarbeit und dem Datenschutz (Artt. 44-50) eine Bestimmung zum „Status der Kirchen und weltanschaulichen Gemeinschaften“. Art. 51 liest sich wie folgt:

(1) Die Union achtet den Status, den Kirchen und religiöse Vereinigungen oder Gemeinschaften in den Mitgliedstaaten nach deren Rechtsvorschriften genießen, und beeinträchtigt ihn nicht.

(2) Die Union achtet den Status von weltanschaulichen Gemeinschaften in gleicher Weise.

(3) Die Union pflegt in Anerkennung der Identität und des besonderen Beitrags dieser 
Kirchen und Gemeinschaften einen offenen, transparenten und regelmäßigen Dialog mit ihnen. (Hervorhebungen durch den Autor).

In seinen Absätzen 1 und 2 ist diese Kirchenklausel eine vollinhaltliche Übernahme der so genannten „Amsterdamer Kirchenerklärung“. Letztere war bereits der Schlußakte des Amsterdamer Vertrages ${ }^{50} \mathrm{im}$ Jahre 1997 angefügt worden und findet sich nach geltender Rechtslage als Erklärung Nummer 11 des EU-Vertrages wieder. Als bloße Erklärung (im Unterschied zu einem Protokoll) $)^{51}$ ist sie rechtlich nicht bindend, aber als begleitendes Dokument eine zwingende Interpretationshilfe bei der Auslegung der Verträge. ${ }^{52}$ Mit diesem Dokument wurde 1997 erstmals das große Schweigen vis a vis den Kirchen durchbrochen. ${ }^{53}$ Die Amsterdamer Kirchenerklärung geht auf eine gemeinsame, von der Bundesregierung unterstützte Initiative der deutschen Kirchen, der EKD und der Deutschen Bischofskonferenz, zurück. ${ }^{54}$ Es wurde behauptet, dass die Amsterdamer Kirchenerklärung eine "negative Kompetenzbestimmung“, ja gar eine Anleitung zur „positiven Ausgestaltung einer Kompetenzausübung" sei. ${ }^{55}$ Dies ist aber bis auf weiteres in dieser Stringenz aufgrund der juristischen Normenqualität der Erklärung, zu bezweifeln. Nichtsdestotrotz gibt die Erklärung dem EuGH ein zusätzliches Argument an die Hand, um eventuell „kirchenbedrohendes“ Sekundärrecht kritisch zu hinterfragen bzw. in seiner Rechtssprechung den status der Kirchen, den diese „in den Mitgliedstaaten nach deren Rechtsvorschriften" genießen, weitest möglich zu respektieren. Gerade weil aber die Normenqualität der Amsterdamer Kirchenerklärung zu wünschen übrig lässt, ist die nun im Verfassungsvertrag vorgeschlagene Hebung dieser Norm in den Rang des Primärrechts von erheblicher Bedeutung. Eine solche Entwicklung ist als beträchtlicher Erfolg für die Kirchen und Religionsgemeinschaften zu werten. ${ }^{56}$
Von großer Bedeutung ist der dritte, nämlich neue Absatz der Kirchenklausel. In seinem Anerkennungsteil wird die Rolle der Kirchen und Gemeinschaften - wohl im Zusammenhang mit dem demokratischen Leben der Union schlechthin - anerkannt. In seinem Verpflichtungsteil erklärt die Union, einen regelmäßigen und offenen Dialog mit den Kirchen und Gemeinschaften aufrechtzuerhalten. Dieser neue passus zeichnet bisherige Praxis nach, ${ }^{57}$ etabliert aber für die Zukunft eine Pflicht, die Kirchen in einen, wenn auch nicht zwingend institutionalisierten, so doch „regelmäßigen“ Dialog einzubinden. Dies eröffnet den Kirchen neue Möglichkeiten, sich effizient in den Willensbildungsprozess der Union an prominenter Stelle einbringen zu können (dazu noch weiter unten).

\section{II.c. Die Grundrechte}

Die Religionsverweise des Verfassungsvertrages im Kontext der Grundrechte stellen keine substantielle Neuerung dar. Die Bestimmungen des Teil II des Vertrages sind ja lediglich aus der (freilich nach wie vor per se noch nicht bindenden) Grundrechtecharta entnommen, welche wiederum großteils auf die Judikatur des Gerichtshof in Luxembourg zurückgreifen hatte können (letzterer wiederum stützt sich in Sachen Grundrechte wesentlich auf die Europäische Menschenrechtskonvention des Europarates, der EMRK).

Von Relevanz ist hier nahe liegender Weise die Religionsfreiheit. Der erste Entwurf der Charta beschränkte sich noch in verbissener Kürze auf die individuelle Religionsfreiheit (,Jede Person hat das Recht auf Gedanken-, Gewissens- und Religionsfreiheit" $)^{58}$ und blieb damit hinter dem einschlägigen Artikel 9 der EMRK zurück, welchen die EU bereits über ihre allgemeine Wertebestimmung im EU-Vertrag zu „achten“ verpflichtet ist (siehe Art. 6 Abs. 2 EU). Unter der Überschrift „Gedanken-, Gewissens- und Religionsfreiheit" heißt es nun (in inhaltlicher Übereinstimmung mit der EMRK) in Artikel 10 des Verfassungs- 
vertrages:

(1) Jeder Mensch hat das Recht auf Gedanken-, Gewissens- und Religionsfreiheit. Dieses

Recht umfasst die Freiheit, seine Religion oder Weltanschauung zu wechseln, und die Freiheit, seine Religion oder Weltanschauung einzeln oder gemeinsam mit anderen öffentlich oder privat durch Gottesdienst, Unterricht, Bräuche und Riten zu bekennen.

(2) Das Recht auf Wehrdienstverweigerung aus Gewissensgründen wird nach den einzelstaatlichen Gesetzen anerkannt, welche die Ausübung dieses Rechts regeln. (Hervorhebung durch den Autor)

Was mögliche Einschränkungen der Religionsfreiheit betrifft, verweisen die Erläuterungen der EU Grundrechtscharta auf Art. 9 Absatz 2 der EMRK. Diese Erläuterungen des ersten Konvents sind nun gemäss Verfassungsvertrag von den Gerichten und Mitgliedstaaten "gebührend" zu „berücksichtigen“. 59

Paragraph 2 dieser Bestimmung macht in seinem Verweis auf das mitgliedstaatliche Recht deutlich, dass sich die Unionsebene zurückhält, und den Mitgliedstaaten gebührenden Spielraum lässt, wenn es um religionsnahe Bereiche geht. Ähnliches findet sich im Bildungsbereich. Art. II-14 des Verfassungsvertrages regelt das Recht auf Bildung wie folgt:

(1) Jeder Mensch hat das Recht auf Bildung sowie auf Zugang zur beruflichen Ausbildung

und Weiterbildung.

(2) Dieses Recht umfasst die Möglichkeit, unentgeltlich am Pflichtschulunterricht teilzunehmen.

(3) Die Freiheit zur Gründung von Lehranstalten unter Achtung der demokratischen Grundsätze sowie das Recht der Eltern, die Erziehung und den Unterricht ihrer Kinder entsprechend ihren eigenen reli- giösen, weltanschaulichen und erzieherischen Überzeugungen sicherzustellen, werden nach den einzelstaatlichen Gesetzen geachtet, welche ihre Ausübung regeln. (Hervorhebungen durch den Autor).

Die Neuerung des Verfassungsvertrages im Bereich der Grundrechte wäre - soweit er denn in Kraft tritt - dass nicht nur einzeln ausjudizierte Rechte, sondern der voll ausformulierter Katalog der Charta im Teil II des Vertrages rechtlich bindend werden würde. Dies mag weniger Bedeutung für die (größtenteils bereits konsolidierte) Rechtssubstanz als für die „integrationspsychologische“ Außenwirkung eines solchen ausformulierten Kataloges in Verfassungsrang haben.

\section{II.d. Nichtdiskriminierung}

Das Diskriminierungsverbot des Gemeinschaftsrecht war lange von primitivem Entwicklungsstand. Traditionelles Herz der EUDiskriminierungspolitik ist die Vermeidung jeglicher Art von Diskriminierung (und, wie der Gerichtshof alsbald feststellte, auch bloßer Benachteiligung) aufgrund der Staatszugehörigkeit. Andere Diskriminierungstatbestände - mit der Ausnahme der Diskriminierung zwischen den Geschlechtern - spielten lange keine Rolle. Dies erklärt sich mit der wirtschaftsrechtlichen Zielrichtung der EWG. Wirtschaftspolitische Protektionsversuche der Mitgliedstaaten konnten mit dem durchschlagenden Diskriminierungstatbestand der Staatsangehörigkeit ausreichend und effizient bekämpft werden. Mit der zunehmenden Ausweitung der EU-Politikbereiche und einer „Politisierung“ der Wirtschaftsgemeinschaft weitete sich auch das Diskriminierungsverständnis des Gemeinschaftsrechts im Rahmen der EuGH Judikatur aus. Mit dem Vertrag von Amsterdam wurde schließlich der Europäischen Union die Kompetenz eingeräumt, Diskriminierung aufgrund der verschiedensten Merkmale zu bekämpfen. Konsequenterweise verbietet die Grundrechtecharta nicht nur Diskriminierung aufgrund der Staatsan- 
gehörigkeit, sondern auch all jene Diskriminierungsmerkmale die im aktuellen Art. 13 EG aufgelistet sind, folglich auch solche aufgrund der Religionszugehörigkeit. ${ }^{60}$ Entsprechenderweise liest sich das Diskriminierungsverbot des Art. II-21 des Verfassungsvertrages wie folgt:

(1) Diskriminierungen insbesondere wegen des Geschlechts, der Rasse, der Hautfarbe, der

ethnischen oder sozialen Herkunft, der genetischen Merkmale, der Sprache, der Religion oder der Weltanschauung, der politischen oder sonstigen Anschauung, der Zugehörigkeit zu einer nationalen Minderheit, des Vermögens, der Geburt, einer Behinderung, des Alters oder der sexuellen Ausrichtung sind verboten.

(2) Im Anwendungsbereich der Verfassung ist unbeschadet ihrer einzelnen Bestimmungen jede Diskriminierung aus Gründen der Staatsangehörigkeit verboten. (Hervorhebung durch den Autor)

Die Bestimmung zur Diskriminierungspolitik der Europäischen Union spiegeln den momentanen Art. 13 EG wieder und finden sich in Teil III des Verfassungsvertrages. In einer Querschnittsklausel heißt es dazu vorab (Art. III-3):

Bei der Festlegung und Durchführung der Politik und der Maßnahmen in den in diesem Teil genannten Bereichen zielt die Union darauf ab, Diskriminierungen aus Gründen des Geschlechts, der Rasse, der ethnischen Herkunft, der Religion oder der Weltanschauung, einer Behinderung, des Alters oder der sexuellen Ausrichtung zu bekämpfen. (Hervorhebungen durch den Autor).

Die eigentliche Politikbestimmung findet sich dann in Art. III-8 des Verfassungsvertrages, der wie folgt lautet:
(1) Unbeschadet der sonstigen Bestimmungen der Verfassung und im Rahmen der durch die

Verfassung auf die Union übertragenen Zuständigkeiten können die für die Bekämpfung von Diskriminierungen aus Gründen des Geschlechts, der Rasse, der ethnischen Herkunft, der Religion oder der Weltanschauung, einer Behinderung, des Alters oder der sexuellen Ausrichtung erforderlichen Maßnahmen durch ein Europäisches Gesetz oder Rahmengesetz des Ministerrates festgelegt werden. Der Ministerrat beschließt einstimmig nach Zustimmung des Europäischen Parlaments.

(2) Die Grundprinzipien für die Fördermaßnahmen der Union und solche Maßnahmen selbst, mit denen die Maßnahmen der Mitgliedstaaten unterstützt werden sollen, können unter Ausschluss jeglicher Harmonisierung der Rechts- und Verwaltungsvorschriften der Mitgliedstaaten durch Europäische Gesetze oder Rahmengesetze festgelegt werden. (Hervorhebungen durch den Autor).

Für den Bereich der Diskriminierungspolitik ist somit festzuhalten, dass der Verfassungsvertrag keine Neuerungen mit sich bringt. Inwiefern die Rechtsetzungsgrundlage für eine weiter ausformulierte Antidiskriminierungspolitik im Bereich der Religion genützt wird, ist Sache des Europäischen Gesetzgebers. Diesbezüglich ist anzumerken, dass das Erfordernis der Einstimmigkeit im Rat aufrecht bleiben soll, was einen beträchtlichen prozeduralen Hemmschuh darstellt. Bislang wurden erst zwei legislative Maßnahmen auf der Grundlage des aktuellen Art. 13 EG erlassen. Die Richtlinie zur Festlegung eines allgemeinen Rahmens für die Verwirklichung der Gleichbehandlung in Beschäftigung und Beruf (RL 2000/78/EG) ist u.a. bestrebt, Diskriminierungen aus Gründen der Religion zu unterbinden. Die so genannte Rassendiskriminierungsrichtlinie, die sich nicht nur auf die Bereiche Beschäftigung und Beruf bezieht, sondern viel weiter gefasst ist, kon- 
zentriert sich hingegen ausschließlich auf den Diskriminierungstatbestand der Rasse. Als indirekte Diskriminierung kann jedoch auch religiös motivierte Diskriminierung in den Anwendungsbereich dieser Richtlinie kommen. ${ }^{61}$

\section{II.e. Die Vielfaltsklauseln}

An einem weiteren Ort enthält der Verfassungsvertrag einen Religionsbezug. Auch hierbei handelt es sich jedoch um keine originär konventsbedingte Neuerung, sondern um die Übernahme einer (rechtlich bislang nicht bindenden) Bestimmung, die sich bereits in der Grundrechtecharta findet. ${ }^{62}$ Tritt der Vertrag in Kraft dann würde die folgende Bestimmung in Rechtskraft erwachsen (Art. II-22: „Vielfalt der Kulturen, Religionen und Sprachen"):

„Die Union achtet die Vielfalt der Kulturen, Religionen und Sprachen." (Hervorhebung durch den Autor)

Eine ähnliche Querschnittsklausel gibt es bereits nach bindenden geltendem Recht im Bereich der Kultur. Art 151 EG verpflichtet die Union „ihre" Vielfalt der Kulturen in all ihren Tätigkeiten (auch) außerhalb der Kulturpolitik einerseits zu respektieren, andererseits zu fördern. Diese Art „Vielfaltsverträglichkeitsklausel“ wurde in Art. III-181 Abs. 4 des Verfassungsvertrages übernommen ${ }^{63}$ :

„Die Union trägt bei ihrer Tätigkeit aufgrund anderer Bestimmungen der Verfassung den kulturellen Aspekten Rechnung, insbesondere zur Wahrung und Förderung der Vielfalt ihrer Kulturen."

Soweit Religion als Ausdruck kultureller Vielfalt betrachtet werden kann, ist sie somit bereits jetzt - unabhängig vom Inkrafttreten des Verfassungsvertrages - geschützt. Da Religion in ihrem kulturellen
Reichtum Traditionen mitbewahrt und nationale wie regionale Identitäten mitträgt, wenn nicht gar verkörpert, fällt sie auch partiell in den Schutzbereich der nationalen Identität. Letztere ist seit dem Vertrag von Maastricht explizit in den Verträgen geschützt. Art. 6 Abs. 2 EU verpflichtet die Union, die Identitäten ihrer Mitgliedstaaten zu achten. Auch diese Bestimmung wurde in den Verfassungsvertrag übernommen, dabei aber ausgebaut und präzisiert. Der erste Absatz des Art 5 („Beziehungen zwischen der Union und den Mitgliedstaaten“) liest sich wie folgt:

(1) Die Union achtet die nationale Identität der Mitgliedstaaten, die in deren grundlegender politischer und verfassungsrechtlicher Struktur einschließlich der regionalen und kommunalen Selbstverwaltung zum Ausdruck kommt. Sie achtet die grundlegenden Funktionen des Staates, insbesondere die Wahrung der territorialen Unversehrtheit, die Aufrechterhaltung der öffentlichen Ordnung und den Schutz der inneren Sicherheit.

Interessant ist in diesem Zusammenhang zu vermerken, dass der regionalen und lokalen Selbstverwaltung hier nun eine spezielle Wichtigkeit eingeräumt wurde. Im Konvent hatte es Versuche gegeben, den Religionsbereich an dieser Stelle eine ebenso heraus stechende Rolle zuteil werden zu lassen. Die so genannte Christophersen Klausel hatte vorgeschlagen auch die Beziehungen zwischen Staat und Kirche ausdrücklich in den „EU-sicheren“ Schutzbereich der nationalen Identität zu stellen ${ }^{64}$ Andere wiederum forderten gleiches für die Abtreibungspolitik - ein politisches Absicherungsbedürfnis das auch im Rahmen der Osterweiterung Relevanz bekam: auf Drängen von Polen bzw. Malta wurde dem Beitrittsvertrag ein entsprechendes Protokoll bzw. eine Erklärung beigelegt. ${ }^{65}$

Als weiteres Beispiel für die Notwendigkeit religionsrechtlicher „Bann- 
meilen" lässt sich der Tierschutz anführen. Auch er - gleich wie die Abtreibungspolitik - kein an und für sich religionsrechtliches Thema in sensu strictu. Doch auch hier werden nicht nur religiöse Empfindungen tangiert, sondern religionsrechtliche Bedürfe en passant „mitgeregelt" wie etwa in Fragen des Schächtens deutlich wird. Tatsächlich wurde dies in einem dem Vertrag von Amsterdam beigelegten Protokoll zum Tierschutz wie folgt unterstrichen ${ }^{66}$ :

„... bei der Festlegung und Durchführung der Politik der Gemeinschaft in den Bereichen Landwirtschaft, Verkehr, Binnenmarkt und Forschung tragen die Gemeinschaft und die Mitgliedstaaten den Erfordernissen des Wohlergehens der Tiere in vollem Umfang Rechnung; sie berücksichtigen hierbei die Rechts- und Verwaltungsvorschriften und die Gepflogenheiten der Mitgliedstaaten insbesondere in bezug auf religiöse Riten, kulturelle Traditionen und das regionale Erbe." (Hervorhebung durch den Autor)

Schließlich ist noch das Motto der EU zu erwähnen. Im Gegensatz zu den US hatte die Union bislang kein Motto. Im ersten Artikel des vierten Teils des Verfassungsvertrages werden "die Symbole der Union“ geregelt und im dortigen dritten Absatz heißt es nunmehr:

\section{„Die Devise der Union lautet: in Vielfalt geeint"}

Hierbei haben sich die Verfassungsmütter und -väter wohl auf die Devise „in varietate concordia“ stützen können, die auf der Grundlage eines europaweiten Schülerwettbewerbs am 4. Mai 2000 im EU-Parlament als das zukünftige Motto der EU empfohlen wurde. ${ }^{67}$ Vielfalt hat selbstverständlich auch hier eine religiöse Komponente. In Zusammenschau mit anderen Bestimmungen des Vertrages ist wohl davon auszugehen, dass sich diese Bestimmung in erster Linie auf die Vielfalt zwischen den Staaten und weniger auf die Vielfalt innerhalb der Staa- ten bezieht. So dürfte die Bestimmung für den Schutz der religionsrechtlichen Ausrichtung der Staaten von Relevanz sein und - bis auf weiteres - weniger darauf abzielen, religiösen Minderheiten in den einzelnen Staaten direkten gemeinschaftsrechtlichen Schutz angedeihen zu lassen. ${ }^{68}$ Es ist allerdings darauf hinzuweisen, dass es berufene Stimmen gibt, die die Vielfaltsverpflichtung der EU wie sie sich aus Art. 22 der Charta ergibt, geradezu als Minderheitenschutzbestimmung lesen. ${ }^{69}$

\section{Integration und Religion: von Rechtssplittern und Schutz-} klauseln

Im vorhergehenden Kapitel haben wir relevante Stellen der vorgeschlagenen EU-Verfassung betrachtet. Die versprengten Bestimmungen sind weit davon entfernt als EU-Religionsverfassungsrecht bezeichnet werden zu können. Bestenfalls kann man von einzelnen primärrechtlichen Versatzstücken sprechen, die für Fragen des nationalen Religionsrechts von Bedeutung sind. Dieses Normpool zeichnet sich in weiten Teilen durch einen defensiven Charakter aus. Damit ist zweierlei gemeint. Zum einen fehlt es der Union an einer Rechtssetzungskompetenz im Bereich des Religions- oder Kirchenrechts ${ }^{70}$ - sie kann somit im Kernbereich des Religionsrechts gar nicht aktiv rechtssetzend tätig werden. Zum anderen liegt die Bedeutung der Mehrzahl der identifizierten Bestimmungen darin, religionsrechtliche und kirchenrechtliche Bestimmungen auf nationaler (und gegebenenfalls subnationaler) Ebene vor Europäischem Recht abzuschirmen. Das was auf Europäischer Ebene an Sekundärrecht produziert wird (so genannte positive Integration) bzw. das was das Primärrecht etwa in den Grundfreiheiten des Binnenmarktes an Verbotsnormen vorgibt (so genannte negative Integration) muß somit gewisse Bannzonen zugunsten des nationalen Religionsrechts achten. 
Dass man sich vor etwas schützen will, das es auf ersten Blick nicht geben kann, erklärt sich mit dem besonderen Charakter der Union. Für die positive Integration gilt, dass die Kompetenzgrundlagen der Europäischen Verträge funktional und nicht sektoriell definiert sind. Das bedeutet, dass die notwendige Flexibilität auf EU Ebene durch breit definierte Kompetenztatbestände gewährleistet wird. Die EU kann sozusagen „am Rande“ ihrer Kernkompetenzen - wie etwa die Herstellung des Binnenmarktes - in Bereiche „mithineinregieren“, die als Ganzes betrachtet den Mitgliedstaaten vorbehalten sind und die eben in extremis von religionsrechtlicher Bedeutung sein können. Werbezeiten im Fernsehen, Vorschriften für das Schlachtwesen, der Schutz von elektronisch übermittelten Daten, Diskriminierungsschutz für Arbeitnehmer, Arbeitszeitgesetze und so fort sind mitunter Spielfelder nicht nur des nationale Religionsrechts, sondern auch des Gemeinschaftsrechts. ${ }^{71}$ Für die negative Integration ist zu sagen, dass der Gerichtshof traditionell seine vier Grundfreiheiten wie etwa die Arbeitnehmerfreizügigkeit sehr breit auslegt und durch seine Forderung nach strikter Inländergleichbehandlung für alle EU-Bürger den Gesetzgebern wie den Verwaltungen in den Mitgliedstaaten harte Grenzen mit auf den Weg gibt, die auch in Bereichen zum tragen kommen, in denen die Gemeinschaft gar keine Rechtsetzungskompetenz hält. Sachverhalte religiöser oder kirchenrechtlicher Relevanz kommen so in den Anwendungsbereich des Europarechts. Diese Sachlage wurde als „logischer Fehler" bezeichnet. „Das Europarecht versteht die Regelung von Kirchen- und Religionsangelegenheiten nicht als wirtschaftserhebliches Kirchenrecht, sondern als kirchenerhebliches Wirtschaftsrecht. Mit diesem Zugriff auf die Kirchen im Mantel einer Wirtschaftskompetenz bleibt die Kollissionsfrage zwischen autonomen Kirchenrecht, mitgliedstaatlichem Staatskirchenrecht und europäischem Wirtschaftsrecht gänzlich ungelöst" ${ }^{72}$ Was hier somit als Strukturfehler angeprangert wird, lässt sich jedoch in der Europäischen Realität einer eng vernetzten multi level governance nicht auflösen. „Unionsfreie“ Kirchen, die der
Europäischen Union als gleichberechtigte Partner gegenüber stehen, müssen vor dem Hintergrund eine Utopie bleiben, dass mittlerweile jedes Rechtshandeln innerhalb der Union auch eine Europäische Dimension hat.

Das ist keine Kapitulation vor supranationalem Imperialismus, sondern die Anerkennung, dass starre selbstsuffiziente Normenstrukturen abgelöst wurden von interaktiven Vermittlungsprozessen zwischen Rechtsquellen verschiedenster Derivanz.

Der Bereich der Religion kann in diesem Zusammenhang ebenso wenig eine kategorische Ausnahme für sich in Anspruch nehmen wie andere politisch sensible Bereiche wie etwa die Sprachpolitik, die Kulturpolitik oder der Schutz von Minderheiten. Der Europäische Einfluss kann in diesem Zusammenhang neutraler Natur sein (das heißt, zu einem Anpassungsbedarf führen, der nicht den eigentlich relgionsrelevanten Gehalt betrifft) oder aber tatsächlich die religionsrechtliche Identität eines Mitgliedstaates beeinträchtigen. ${ }^{73}$ Ein Beispiel für ersteres ist etwa das jüngste Urteil zur Datenschutzrichtlinie, in welchem Ende 2003 festgehalten wurde, dass das bekannt machen von Krankenständen einer Mitarbeiterin auf der Internet Seite einer Kirchengemeinde der besagten Richtlinie widerspricht. ${ }^{74}$ Es wäre hier nicht einzusehen, warum der faktische Zusammenhang mit einer religionsnahen Tätigkeit eine Ausnahme vom europarechtlichen Datenschutz rechtfertigen sollte. Ein Beispiel für einen delikateren gemeinschaftsrechtlichen Einfluss ergibt sich aus der Möglichkeit der Kirchen und Tendenzbetriebe in ihrer Anstellungspolitik nach Religion und Weltanschauungskriterien zu diskriminieren. Art. 13 EG steht nämlich mit solchen Regelungen in potentiellem Konflikt. Tatsächlich verankerte aber der EU-Gesetzgeber in den beiden oben erwähnten ausführenden Richtlinien einen entsprechenden Ausnahmetatbestand, sodass diese Spannung gelöst ist. In Fällen eines gespannten Dialogs zwi- 
schen Gemeinschaftsrecht und nationalem Religionsrecht können die oben geschilderten „Bannmeilen“ im Primärrecht von Relevanz sein. Wenn auch nicht eine Klausel wie die Christopherson Klausel Eingang in den Verfassungsvertrag genommen hat, so ist es doch von Bedeutung, dass Artikel 22 der Charta mit dem Verfassungsvertrag in Rechtskraft erwächst und in Zusammenschau mit Art. 5 des Verfassungsvertrages das primärrechtliches Schutzschild zugunsten der religionsrechtlichen Identität der Mitgliedstaaten weiter verstärken würde. ${ }^{75}$ Die Bedeutung eines solchen, wenn auch vage formulierten, Schutzschildes ist für den Kollisionsfall nicht zu unterschätzen. ${ }^{76}$ Ähnliches ist zum neuen Art. 51 des Verfassungsvertrages zu sagen. Der vielleicht in Bälde primärrechtlich garantierte Dialog mit den Kirchen (Art. 51 des Verfassungsvertrages) garantiert ihnen, sich frühzeitig zu Rechtsetzungsprojekten einbringen zu können, die für die Europäischen Kirchen bzw. nationales Religionsrecht von Relevanz sein könnten. In diesem Zusammenhang sei den Kirchen geraten, sich die nationalen Parlamente zu Partnern ihrer Anliegen zu machen. Schließlich werden diese im Rahmen des neuen "early warning mechanisms" ermächtigt, über die Einhaltung des Subsidiaritätsprinzips zu wachen. ${ }^{77}$ Normen, die drohen exzessiv in das nationale Kirchenrecht hineinzuregieren, stehen unter Umständen auch in Verdacht das Subsidiaritätsprinzip zu verletzen. Eine entsprechende Eingabe eines Drittels nationalen Parlamentes zwingt die Kommission den Vorschlag zurückzunehmen und neu zu überdenken. Weiters ist darauf zu drängen, dass die Vielfaltsverträglichkeitsklausel im momentanen Art. 151 Abs. 4 EG besonders auch mit Hinblick auf religiöse Sensibilitäten genützt wird.

Abschließend bleibt zum Thema „EU-Religionsrecht“ zu sagen, dass es sehr wohl Interaktionen zwischen EU und religionsrechtlichem Normenbestand gibt. Allerdings nicht in der Form, dass die EU genuin Religionsrecht gestaltet, sondern es ohne religionspolitische Absicht hier und da sekundärrechtlich wie auch primärrechtlich mitberührt.
Daneben garantiert die EU im Primärrecht zum einen grundrechtlich die Religionsfreiheit des einzelnen und gibt zum anderen den Staaten in Form von Schutzklauseln ein Instrumentarium zur Hand, welches vor allzu intensiver Ingerenz in mitgliedstaatliche Religionsrechtsbestand schützen soll. Bereichsausnahmen bzw. das Einräumen von entsprechenden Gestaltungsfreiräumen finden sich entsprechend im Sekundärrecht. Bei so wenig konzeptuellem, werttragendem Normbestand schleicht sich allerdings die Frage ein, ob die Union nur dem einzelnen Individuum Religionsfreiheit garantiert und sich den Staaten gegenüber verpflichtet deren „Freiheit", also legislativen Handlungsspielraum, nicht zu sehr einzuschränken, aber sonst ein Europa verkörpert, das religionsfrei ist. Ein Europa also, das zwar „Voll Religionsfreiheit" aber ansonsten „religionsentleert" ist?

\section{EU-Religionsidee - viel Lärm um nichts?}

Die bisherigen Ausführungen, insbesondere zu den einstweiligen Ergebnissen der Verfassungsdebatte in Form des vom Konvent vorgeschlagenen Verfassungsvertrages, ergeben tatsächlich das Bild von einer Haltung seitens der EU, „die man als wohlwollende Ignoranz gegenüber Kirche und Religion beschreiben könnte". ${ }^{78}$ Deshalb hier mit einem „viel Lärm um nichts“ zu schließen wäre aber wohl voreilig. Allenfalls kann man schlussfolgern, dass die EU hinsichtlich der Religion hinter dem religiösen Erbe Ihres Kulturterritoriums, nämlich Europa zurückbleibt. Aus historischer Sichtweise ist das Christentum immerhin einer der "drei Hügel“, die das Fundament Europas ausmachen: ${ }^{79}$ neben Palatin (römisches Rechtsystem) und Olymp (griechische Kultur) verkörpert das Christentum mit dem Berg Golgotha die dritte Identität stiftende kulturelle Erhebung auf welcher Europa als Kulturraum fußt. $\mathrm{Ja}$, ohne die Europa, wie es steht und lebt, geradezu undenkbar wäre. ${ }^{80}$ Anstatt die transzendentale (Mit)anknüpfung der Europäischen Identität anhand einer Unzahl von Zitaten und historischen Exkursen zu be- 
legen, sei hier aus einer Rede Vaclav Havels zitiert, in welcher er 1994 eine Charta der Europäischen Union forderte "die klar die Ideen zu definieren hätte, auf denen sie [die EU] beruht, den Sinn, den sie hat, und die Werte, die sie zu verkörpern trachtet" ${ }^{81}$ In der Rede heißt es:

„Die Europäische Union beruht auf einem großen Ensemble zivilisatorischer Werte, deren Wurzeln zweifellos auf die Antike und das Christentum zurückgehen und die sich durch zwei Jahrtausende hindurch zu der Gestalt entwickelt haben, die wir heute als die Grundlagen der modernen Demokratie, des Rechtsstaates und der Bürgergesellschaft begreifen. Das Ensemble dieser Werte hat sein klar umrissenes sittliches Fundament und seine manifeste metaphysische Verankerung, und zwar ungeachtet dessen, inwieweit der moderne Mensch sich das eingesteht oder nicht. Man kann also nicht sagen, der Europäischen Union mangele es an einem eigenen Geist, aus dem alle ihre konkreten Prinzipien, auf denen sie beruht, hervorgegangen sind. Nur scheint es, dass dieser Geist zu wenig sichtbar wird. "82

Ist der Geist wirklich so unsichtbar? Die obige Analyse des Verfassungsrahmens hat bereits gezeigt, das Religion durchaus ein Thema im Integrationsprozess ist. Darüber hinaus sind viele Töne des Spektrums welches das Verhältnis Religion und EU kennzeichnen, nicht streng juridisch erfassbar, sondern vielmehr Fragen des politischen Engagements oder einfach der kulturellen Tatsachen. Dass Religion jedenfalls eine Agenda ist, für die sich die Union einsetzt, zeigt sich beispielsweise im Menschenrechtsbereich, wo sich die EU außenpolitisch für religiöse Minderheiten bemüht, etwa für Christen in Turkmenistan, ${ }^{83}$ den Baha'is in Iran, ${ }^{84}$ religiöser Minderheiten in Pakistan oder Indien ${ }^{85}$ oder auch die Religionsfreiheit einzelner Individuen ${ }^{86}$. All das kann aber unsere Beurteilung auf normativer Ebene nicht ändern. Eine sehr plastisches Bild vom prinzipiellen Zugang der EU zum Thema Religion bietet eine Stellungnahme der finnischen EU-Präsidentschaft anlässlich der OSCE review conference im September 1999.87 Darin heißt es unter anderem:

\section{"Matters governing religion, belief and conscience are not to be} decided by the state, but in the individual's conscience. The role of the state is not to decide religious truth, but to promote tolerance so that people can pursue truth as individuals and in communities. Rather than endorsing any particular religion or belief, the EU endorses the notion that people should be free - at any time - to have, to profess, to maintain, to adopt, and to change their own beliefs....

... We acknowledge that manifestations of some new religious movements may present challenges as well as difficult issues for modern democratic states. Such issues may involve education for their children, conscientious objection to military service, unusual recruitment methods, peculiar lifestyles, and unorthodox beliefs. To accommodate such situations and to ensure that religious activities are in keeping with the principles underlying democratic societies, international human rights instruments stipulate the countervailing interests that may justify limiting certain religious manifestations."

(Hervorhebung durch den Autor)

Das bestätigt unsere Zweifel. Die Union hat keine selbständige Idee von Gott, von Religion und von den Kirchen. Sie hat höchstens eine Idee davon, wie Beziehungen ihrer Mitgliedstaaten zu diesen drei Phänomenen aussehen können (aber nicht müssen). Die Vielfalt an Haltungen, die die 25 Staaten vis a vis Kirchen und Religion einnehmen, erfordert es, dass die Union sich zu zurückhaltender Neutralität verpflichtet fühlt. ${ }^{88}$ Von der EG/EU als juristische Person, die sich ganz wesentlich legitimatorisch auf ihre Mitgliedstaaten, den Herren der Verträge, abstützt, ist keine Religionsidee zu erwarten, die wesentlich über eine Religionsfreiheit des Individuums hinausgeht. Dass ein Gottes- 
bezug der EU im Rahmen einer Verfassungsdebatte (die als solche unter dem Fallbeil der letztendlich erforderlichen Einstimmigkeit unter den Staaten geführt wird) auch politisch wenig realistisch ist, ergibt sich aus gleichem Grunde. Neben den so „religionsnahen“ Verfassungen Irlands (die gar im Namen der Dreiheiligkeit verkündet wird), Englands (wo die Chefin der Staatskirche auch dem Staat selbst vorsteht), Deutschlands (die immerhin das deutsche Volk in Verantwortung vor Gott stellt), Dänemarks (die die lutherische Kirche zur Nationalkirche erklärt), Griechenlands (die ihre christlich-orthodoxe Kirche als dominant beschreibt) oder jener Maltas (die die katholische Konfession als Staatskirche festlegt und einen entsprechenden Unterricht in allen öffentlichen Schulen vorschreibt) gibt es ebenso pointiert positionierte Mitgliedstaaten wie Frankreich, die den Laizismus zum Verfassungsprinzip erklären.

Sollen wir uns folglich damit zufrieden geben, dass nun am Ende der zähen "Gottesfrage" im Europäischen Konvent eine derartig schwammige Formel wie jene der "religiösen Überlieferungen“ drauf und dran ist, den einzigen „überirdischen Anker" der zukünftigen EU-Verfassung Europas abzugeben? Ich denke nein. Dies ist ein Kompromiss, der nicht befriedigt. Ein Schweigen zu Gott und der Religion wird ebenso wenig dem Neutralitätsgebot gerecht wie der vorgeschlagene Gottesbezug. Die EU Verfassung muss zwei Sensibilitäten beachten - die religiöse Sensibilität (Religionsfreiheit) wie auch die laizistische Sensibilität (Freiheit von der Religion). Jeden Verweis auf Gott zu unterlassen ist somit kein agnostischer Standpunkt, sondern ebenso eine Verletzung des Neutralitätsgebotes. ${ }^{89}$ Als Ausweg aus dieser Bredouille wurde - wie schon erwähnt - eine an die polnische Verfassung angelehnte Formulierung vorgeschlagen. ${ }^{90}$ Zur Erinnerung nochmals die im Rahmen des Konvents vorgeschlagene Formulierung:,,Die Werte der Europäischen Union umfassen die Wertvorstellungen derjenigen, die an Gott als die Quelle der Wahrheit, Gerechtigkeit, des Guten und des
Schönen glauben, als auch derjenigen, die diesen Glauben nicht teilen, sondern diese universellen Werte aus anderen Quellen ableiten".

Ist dies eine neutrale Formulierung, die Gottgläubigen wie nicht an Gott Glaubenden in gleicher Weise gerecht wird? Meiner Einsicht nach lassen sich mehrere Zweifel daran hegen. Zum einen stellt diese Formulierung die Werte der Nichtgläubigen als bloße Funktion der Werte der Gläubigen dar. Das heißt, dass sich die Werte der Union konstitutiv ausschließlich aus den Werten der Gottesgläubigen definieren (arg. „Die Werte umfassen...diese universellen Werte aus anderen Quellen ableiten"). Die Werte der Nichtgläubigen sind somit abgeleiteter, sekundärer Natur. Fallen sie mit jenen der Gottesgläubigen zusammenfallen, so sind sie EU-Werte. Soweit die Werte der Nichtgottesgläubigen jenseits dieser Wertemenge liegen, sind sie für die EU irrelevant bzw. fallen zumindest nicht mehr unter "die Werte der Europäischen Union". Zum anderen heißt es etwa in der Italienischen wie auch in der Englischen Fassung, dass die Nichtgottesgläubigen nicht an diese Werte "glauben“, sondern sie lediglich „respektieren („non condividano tale credo ma rispettano" oder "do not share such a belief but respect"). Die deutsche Fassung ist mit seinem „ableiten“ diplomatischer. Unübersehbar bleibt aber die ungeschickte Optik dieser Wortwahl, die den (bloß) Gottesungläubigen jede Glaubensfähigkeit abzustreiten scheint. Dass aber ein "Gottloser" nicht an Werte glauben kann, unterstellt geradezu eine a priori schwächere Anbindung dieser Gruppe an die gemeinsamen (!) Werte. Aus diesen Gründen errichtet die „polnische Formel“ eine Hierarchie zwischen der Wertebindung der Gottesgläubigen und der Gottesungläubigen und ist somit als „Lösung“ des beschrieben Dilemmas abzulehnen. ${ }^{91}$

Wenn aber die Unterlassung eines EU-Gottesbezuges der Europäischen Realität ebenso wenig gerecht wird wie die Etablierung so einer Bezugnahme, wie soll die "Gottesfrage" dann verfassungsrechtlich 
gelöst werden? Für die Bezugnahme auf das Christentum gesprochen: wo ist der Weg, der zwischen EU-Christophobie und EU-Christomanie verläuft?

\section{Und es geht doch: Ein tertium datur für den Gottesbezug in der neuen EU-Verfassung}

Prinzipiell ist anzuerkennen, dass die angestrebte, rechtlich nicht bindende Bezugnahme auf einen gemeinsamen Kulturhumus im Bereich der Religion sicherlich am besten in der Präambel der EU-Verfassung aufgehoben ist. Präambeln haben - auch wenn bei weitem nicht alle EU Staaten die Figur der Verfassungspräambel kennen ${ }^{92}$ - traditionellerweise eine grundlegende Funktion jeder Verfassung zu erfüllen: in juridischer zarter Weise auf einen gemeinsame ethos der verfassten Gemeinschaft hinzuweisen. Weiters ist auch anzuerkennen, dass ein Ziel vorgeben und Antrieb schaffen ureigenste Aufgaben einer Präambel sind. Würde man sich immer am tiefsten gemeinsamen Nenner orientieren, so wären Präambeln sinnentleert. Budelacci führt aus, dass "die Präambel einen Normativitätsüberschuß enthalten muß" und als "Entwicklungsmotor, der zur Modifikation auffordert" fungiere..$^{93}$ In unserem Zusammenhang stellt sich aber die Frage wieweit die EUPräambel die EU-Verfassungsrealität normativ überstrecken darf. Unbestreitbar war die Kirche über lange Zeit einer der Integrationsfaktoren Europas im Bereich der Kultur, Sprache, Schrift und Bildung. ${ }^{94}$ Und nach wie vor mag sie eine gewisse Rolle in der Legitimität EU-Europas spielen. ${ }^{95}$ Dennoch ist das Christentum heute kein ideeller Spiegel mehr, der die gesellschaftliche Realität der Union lückenlos abdecken kann. Und manche Staaten räumen Gott und der Religion so gut wie keinen öffentlichen Raum ein. Das wiederum kann und darf aber kein Argument sein, auf einen Verweis auf Gott und das Christentum in der EUVerfassung ganz zu verzichten. Werterhalt ist mit Aufwand verbunden. Wenn manche behaupten, dass sich der Werte(ver)fall frei nach dem
Gesetz der Entropie ausrichtet, ${ }^{96}$ so scheint es umso angebrachter, auf EU Ebene alle Werte und damit eben auch Gottes- und Kirchenanbindung zum Ausdruck zu bringen und uns ihren Erhalt somit abzusichern.

Da die polnische "Lösung" hier als Scheinlösung betrachtet wird, stellt sich die Frage, wo ein salomonischer, dritter Weg zwischen dem verfassungsrechtlichen Totschweigen von Gott und der anmassenden Überspannung der Präambel mit einem neuen Gottesbezug liegen kann. Die Lösung des Dilemmas liegt im prinzipiellen Zugang. Die Präambel der EU-Verfassung sollte in der Frage des Gottes- und Religionsbezuges nicht einen bundesstaatlichen, sondern einen staatenbündischen Ansatz wählen. Das meint, dass im Zusammenhang mit Gott und Religion nicht von Werten der Union, sondern von Werten der Mitgliedsstaaten der Union zu sprechen ist. So ein Ansatz würde die rechtliche wie politische Wirklichkeit in der EU-Verfassungslandschaft lediglich deklaratorisch nachzeichnen und nicht konstitutiv auf der EU Ebene überhöhen und damit überstrecken. Damit soll nicht die Rolle des Christentums oder Gottes für die EU geschmälert werden. Der hier geforderte Verweis auf die verfassungsrechtliche Realität in den Mitgliedstaaten ist nicht nur verfassungsjuristisch angemessener, sondern politisch auch bei weitem konsensfähiger. Niemand wird sich gegen einen passus wehren, der darauf hinweist, dass in der Hälfte der Verfassungen der Mitgliedstaaten, der Glaube an Gott und die christlichen Kirchen Erwähnung findet. Damit wird auch nicht - wie mancher an dieser Stelle sogleich argwöhnen mag - jegliche Europäische Dimension des Christentums aufgegeben. Die Anbindung an Gott und an die christliche Kirche, wie wir sie in vielen der Mitgliedstaaten finden, ist nämlich Teil des Erbes aller Mitgliedstaaten. Dass wir in der EU einen Mitgliedstaat haben, der wie Irland seine Verfassung mit den Worten beginnt "In the Name of the Most Holy Trinity, from Whom is all authority and to Whom, as our final end, all actions both of men and 
States must be referred „(Präambel) ist gerade Ausdruck des großen gemeinsamen Europäischen Erbes, das auch von Frankreich geteilt wird, welches seine Verfassung aber ganz im Gegensatz dazu mit den Worten beginnt „La France est une République indivisible, laïque, démocratique et sociale" (Art. 1). Auch diese laizistische Einstellung Frankreichs ist aber wiederum Teil des Europäischen Erbes - auch für einen Mitgliedstaat wie Irland. Ähnliches gilt schließlich auch für das historische Erbe. Wer kann ernsthaft behaupten, dass Napoleon ausschließlich Teil des französischen Erbguts darstellt? Im Grunde verhält es sich mit diesem hier propagierten Ansatz ähnlich wie mit den praktizierenden Gläubigen einerseits und den Ungläubigen samt nicht praktizierenden Gläubigen andererseits innerhalb der Mitgliedstaaten: Die Minderheit der praktizierenden Gläubigen hält etwas lebendig was die Mehrheit der nicht praktizierenden Gläubigen bzw. Ungläubigen nicht missen möchte, weil sie es trotz allem als Teil Ihres kulturellen Umfeldes und Erbes betrachtet!

Aus all diesen Gründen ließe sich das religiöse Erbe der EU wie folgt begreifen und könnte von der Regierungskonferenz entsprechend im Verfassungsvertrag nachgezeichnet werden:

"Gott und den Kirchen wird in Verfassungen einiger Mitgliedstaaten beträchtliche Bedeutung beigemessen. Verfassungen anderer Mitgliedsstaaten sind hingegen von Laizismus gekennzeichnet. Diese Vielfalt an stark abweichenden Zugängen der Mitgliedstaaten zum religiösen Bereich basiert nichtsdestotrotz auf einem gemeinsamen religiösen Erbe Europas, welches sich aus dem Christentum, aber auch aus dem Judentum und dem Islam speist, und verkörpert somit die EU Devise „in Vielfalt geeint“.”

Mit diesem staatenbündischen Zugang in der Gottesfrage, lässt sich das religiöse Erbe gebührend berücksichtigen ohne die Union norma- tiv zu überfordern. Auf der politischen Seite bieten sich die Vorteile, dass so eine Formulierung zum einen mehr Chancen hätte von den Mitgliedstaaten angenommen zu werden als ein Gottesbezug der EU selbst und, zum anderen, dass diese Formulierung die Signalwirkung einer Wagenburg „Europa Cristiana“ vermeidet. Dies scheint nicht unerheblich, in Zeiten in denen Europa - wie eingangs ausgeführt - zunehmend zum inklusiven, vermittelnden Pol zwischen Amerika und den (nicht nur) arabischen Staaten wird.

Zum Abschluss lässt sich festhalten, dass die Europäische Union mehr bietet als bloße Religionsfreiheit. Sie ist auch nicht religionsfrei. Allerdings hat sie keine originäre Religionsidee. Vielmehr verinnerlicht die Union Religionsideen, die allesamt trotz ihrer Vielfalt in einem Europäischen Erbe eine Einheit finden. Eine Einheit übrigens, die sich bereits aus einer Überschneidung der verkündeten Werte ergibt. Die Kirchen wie auch die Europäische Union teilen folgendes „eu angelion“ (griech. für „frohe Botschaft"): Sozialer Verantwortung, sozialer Gerechtigkeit, Menschenwürde, Versöhnung, friedliche Konfliktlösung oder Bekämpfung von Fremdenfeindlichkeit. Es liegt an den Kirchen, die neuen, hier auch aufgezeigten, Möglichkeiten des Verfassungsvertrages zu nützen, um sich in den Integrationsprozess einzubringen und dieses „EU Angelion“ im Trott der Brüsseler Tagespolitik zu unterstützen und stärken. 


\section{Fussnoten}

${ }^{1}$ See J.J.Weiler, Fin-de-siecle Europe: do the new clothes have an emperor?, in The constitution of Europe, in J.J.Weiler, The constitution of Europe, 1999, Cambridge University Press, pp. 238-263, at pp.258-261.

2 Zur Rekonstruktion der Krise siehe etwa Margaretha Kopenig und Christoph Kotanko, Eine europäische Affäre, Wien 2000, Czernin Verlag. Zur Wertedebatte siehe Heinrich Schneider, Die Europäische Union als Wertegemeinschaft auf der Suche nach sich selbst, in: Die Union 1 (2000), S. 11-48.

${ }^{3}$ Siehe zu den Werteverpflichtungen von Beitritts- und Mitgliedstaaten Bruno de Witte und Gabriel N. Toggenburg, Human rights and membership of the European Union, in Steve Peers und Angela Ward, The EU Charter of Fundamental rights, Hart, Oxford 2004, S. 59-82.

${ }^{4}$ Vgl. dazu die so genannte „Bolzano/Bozen Declaration“ sowie umfassende Literaturverweise unter http://www.eurac.edu/pecede

${ }^{5}$ Siehe Schlussfolgerungen unter

http://europa.eu.int/council/off/conclu/dec99/dec99_de.htm

${ }^{6}$ Vgl. auch Art. 28 des Abkommens. Siehe Abkommen zur Gründung einer Assoziation zwischen der Europäischen Wirtschaftsgemeinschaft und der Republik Türkei, in Amtsblatt Nr. P 217 vom 29/12/1964, S. 3687 - 3688.

${ }^{7}$ Neben der Einhaltung des Werteskripts des Art. 6 EU kennt Art. 49 EU nur die Bedingung ein „Europäischer Staat" zu sein. Ende der 80er Jahre wurde das Beitrittsgesuch Marokkos aus eben diesem Grunde abgewiesen. Dennoch ist der Begriff derart dehnbar, dass er schwer eine nützliche Steuerungsfunktion entwickeln wird können.

${ }^{8}$ Artikel 4 der Satzung des Europarates öffnet die Tore zur Mitgliedschaft für jeden „europäischen Staat".

${ }^{\circ}$ Vgl. Etwa G. Avci, Putting the Turkish EU candidacy into context, 7 (2002) European Foreign Affairs Review 91, S. 102.

${ }^{10}$ Das Bevölkerungswachstum ist in der Türkei mit 1, 16\% fast 30 mal höher als in Deutschland mit 0,04\%. Zahlen für 2003 aus dem CIA Factbook,

http://www.cia.gov/cia/publications/factbook/

11 In Deutschland leben rund 3,3 Millionen Moslems (mehrheitlich aus der Türkei), in Frankreich 5 Millionen (mehrheitlich aus Algerien), in Großbritannien 2 Millionen (mehrheitlich aus Pakistan) und in Belgien und den Niederlanden zusammen etwa 1 Millionen (mehrheitlich aus der Türkei und Marokko). In den USA leben 6 Millionen Moslems (aller muslimischer Nationalitäten, vornehmlich Schwarzamerikaner). Zahlen entnommen aus dem Eintrag „Verbreitung des Islam“, in Religion, Brockhaus Verlag, Leipzig 2004, S. 284.
12 Ein EU-weiter Vergleich zur „Causa Kopftuch“ findet sich in Europäischer Informationsbrief, Bildung und Beschäftigung, Nr. 6, 2003 (Herausgeber: EuropaKontakt e.V.), S. 39-54.

${ }^{13}$ Von "cultural shadows" spricht in diesem Zusammenhang Cinzia Piciocchi, Europe faces cultural diversity: towards a European Multicultural Model?, in Francesco Palermo and Gabriel N. Toggenburg (eds.), European constitutional values and cultural diversity, Eurac, Bolzano 2003, S. 25-36, auf S.32.

${ }_{14}$ Siehe zu alledem Mathias Rohe, IPL as sluice importing Islamic rules in Germ any and Europe (Arbeitstitel), in European Yearbook on Minority Issues, EYMI, Volume 3 (2003/4), Kluwer Law International, The Hague, erscheint 2004. Siehe auch Erik Jayme, Multicultural Society and Private Law. German experiences, Saggi, conferenze e seminari, numero 33, Centro di studi e ricerche di dirito comparato e straniero, Roma 1999.Siehe auch umfassend Mathias Rohe, der Islam und deutsches Zivilrecht, in Hans-Georg Ebert und Thoralf Hanstein (Hrsg.), Beiträge zum Islamischen Recht, Peter Lang, 2003, S. 35-61.

${ }^{15} \mathrm{Vgl}$. etwa Robert Kagan, Macht und Ohnmacht. Amerika und Europa in der neuen Weltordnung, Siedler Verlag, München 2003.

${ }^{16}$ Siehe als illustratives Beispiel etwa den Beitrag „Der Glaube der Ungläubigen. Welche Werte hat der Westen?, in: Der Spiegel 52/2001.

${ }^{17}$ Für den Text der erstaunlichen Wortmeldung siehe Europe Daily Bulletins, No. 8058, 28 September 2001.

${ }^{18}$ Romano Prodi, Die Bedeutung des Dialogs, Rede 02/114, gehalten am 20. März 2002 in Brüssel.

${ }_{19}$ Siehe dazu das Strategiepapier der Europäischen Kommission,

http://europa.eu.int/comm/world/enp/pdf/strategy/Strategy_Paper_DE.pdf

20 "With 14centuries of history, 1.3 billion adherents on every continent, the soul of Islam rings with hundreds of different tones, schreibt etwa Yasmin Alihabai-Brown, What perspectives for Islam and Muslims in Europe? An overview, Commentary of the European policy Centre, February 2004,

http://www.theepc.net/en/default.asp?TYP=TEWN\&LV=187\&see=y\&t=\&PG=TEWN/ $E N /$ detail\&l=2\&Al=346

${ }^{21}$ Article 2, section 1 , clause 8 sieht nur folgende Worte vor:

"I do solemnly swear (or affirm) that I will faithfully execute the Office of President of the United States, and will to the best of my Ability, preserve, protect and defend the Constitution of the United States."

22 Gesetz vom 30 Juli 1956, 70 Stat. 732.36 US Code 186.

${ }^{23}$ In Europa findet sich ein "God zij met ons" lediglich auf der nationalen Seite einer Euro Münze - der niederländischen 2 Euro Münze.

${ }^{24}$ So B.A.Robinson, The US national mottos, 
http://www.religioustolerance.org/nat mott.htm

${ }^{25}$ Allegheny, 492 U.S.

${ }^{26}$ Aronow v. United States, 432 F.2d 242 (1970)

${ }^{27}$ Es geht um die Klage von Michael A. Newdow, ein Atheist aus Sacramento und den 9th U.S. Circuit Court of Appeals (damit ist das Urteil mittelbar von Bedeutung für: Alaska, Arizona, California, Hawai, Idaho, Montana, Nevada, Oregon, Washington state).

${ }^{28}$ Zitiert nach B.A.Robinson, The U.S. Pledge of Allegiance,

http://www.religioustolerance.org/nat pled3.htm

${ }_{29}$ Siehe beispielhaft etwa Burkhard Müller, Wir sind Heiden, Süddeutsche Zeitung vom 24/25 April 2004, der unter anderen meint, dass die Kirchen auch körperlich so "dysfunktional [seien] wie ein Parkhaus, wenn es dermaleinst keine Autos mehr geben sollte, sei.

30 J.H.H. Weiler, Un'Europa cristiana, un saggio esplorativo, RCS libri, Milano 2003 ${ }^{31}$ Bischof Martin Hein, Gott in der Verfassung, abrufbar unter

http://www.ekkw.de/bischof/publikationen.html?publikationen/gott-verfassung/ index.html

Diesen pragmatischen Aspekt der transzendentalen Abindung zur Steigerung des ethischen Bewusstsein gegenüber der Schöpfung mag man bereits im "Gottestaat" von Augustinus finden. Dort heißt es unter anderem, dass „Eine Hausgemeinschaft aber von solchen, die aus dem Glauben leben, erwartet die ewigen Güter, die für die Zukunft verheißen sind, und gebraucht die irdischen und zeitlichen Dinge nur wie ein Gast,.. Zitiert nach Norbert Hoerster (Hrsg.), Klassische Texte der Staatsphilosophie, 10. Auflage 1999, DTV München, S. 73.

${ }^{32}$ Bischof Martin Hein, aaO

${ }^{33}$ So etwa Armin von Bogdandy, the Preamble, in Bruno de Witte (ed.), Ten reflections on the Constitutional Treaty for Europe, European University Institute, Florence 2003 S. 3-11, auf S. 6

${ }^{34}$ Der „Entwurf eines Vertrages über eine Verfassung für Europa“ findet sich in allen Sprachversionen unter http://european-convention.eu.int/

${ }^{35}$ Davon gibt es in dem einen Verfassungsvertrag irritierenderweise zwei Stück: eine leitet den Vertrag als ganzes ein, eine zweite lediglich dessen zweiten Teil, de die Charta der Grundrechte enthält.

${ }^{36}$ Zur Natur der Präambel in diesem Zusammenhang siehe Orlando Budelacci, Gott, die Griechen und die neue EU-Verfassung - philosophische Reflexionen zu Verfassungspräambel. Erscheint im Sammelband des Forschungskolloquiums: "Legitimationsgrundlagen der Europäischen Union" (Philosophisches Seminar der Universität Zürich)

${ }^{37}$ Siehe etwa die Formulierung „Schöpfend aus ... sowie aus dem Gottesglauben des Christentums und anderen Religionen...., wie von Erwin Teufel vorgeschlagen Die Änderungsanträge zur Präambel finden sich auf der Konventsseite http:// european-convention.eu.int/

${ }^{38}$ So der Änderungsantrag der polnischen Delegation im Konvent, der von etwa dre Dutzend Konventsmitgliedern unterstützt wurde.

${ }^{39}$ So etwa der Änderungsantrag von Würmeling, Wittbrodt, Fogler, Tusek und Figel oder jener von Inglott, Frendo und Inguaenez.

${ }^{40}$ Präsentiert von Elmar Brok und mitunterzeichnet von Tajani sowie Martikonis

${ }^{41}$ Siehe dazu detailliert Matthias Triebel, Religion und Religionsgemeinschaften im künftigen Europäischen Verfassungsvertrag, Die Debatten des Europäischen Konvents, NomoK@non-Webdokument:

http://www.nomokanon.de/abhandlungen/014.htm

sowie vorher bereits derselbe, Die Zukunft Europas und der Beitrag der Kirchen. Eine Auswertung der kirchlichen Stellungnahmen gegenüber dem Europäischen Konvent, NomoK@non-Webdokument:

http://www.nomokanon.de/abhandlungen/012.htm

Siehe auch die einschlägige Link-Sammlung unter:

http://www.uni-trier.de/ ievr/EUKonvent/beitraege.htm

${ }^{42}$ Siehe http://europa.eu.int/futurum/forum_convention/doc_en.htm

${ }^{43}$ Siehe zur Transparenz im Konvent Gabriel N.Toggenburg, Vertragsänderung im Tandem: Regierungskonferenz und Europäischer Konvent, in European Law Reporter 2002/11, 398-402.

44 und wenn dann nur in sehr sanften Formulierungen wie etwa „An inclusive reference to the Transcendent provides a guarantee for the freedom of the human person, (siehe das Schreiben der Kommission der Bischofskonferenzen der Europäischen Gemeinschaft vom 21 Mai 2002 im Forum).

${ }^{45} \mathrm{Vgl}$. den dem Konvent unterbreiteten kritischen Standpunkt von Herrn Borrell Fontelles, Let's leave God out of this, CONTRIB 204.

${ }^{46}$ Die polnische Lösung wird etwa auch angepriesen von J.H.H. Weiler, Un

'Europa cristiana, Milano, Biblioteca Universale Rizzoli 2003, insb. S.70 und 71. Weiler nimmt in diesem seinen jüngsten Buch in aller Breite vehement für einen christlichen Bezug in der EU-Verfassung Stellung.

47 Der Brok-Verfassungsvorschlag liest sich - in Bezugnahme auf die polnische Verfassung - wie folgt: „The Union values include the values of those who believe in God as the source of truth, justice, good and beauty as well as of those who do not share such a belief but respect these universal values arising from other sources, Siehe CONV 325/2/02 REV 2, S. 30

48 Siehe CONV 480/03 vom 31. Jänner 2003. Der Text inspiriert sich an der polnischen Verfassung. 
49 Während Teil II wie erwähnt „Die Charta der Grundrechte der Union,, enthält und Teil IV „Allgemeine und Schlussbestimmungen, regelt, finden sich im weitaus längsten Teil III „Die Politikbereiche und die Arbeitsweise der Union,..

${ }^{50}$ der am 2.10.1997 unterzeichnet wurde und am 1.5.1999 in Kraft trat.

$51 \mathrm{Vgl}$. etwa die unten erwähnten Protokolle zum Tierschutz bzw. der Abtreibung.

52 Vgl. Art. 31 Abs. 2 lit. b der Wiener Vertragsrechtskonvention.

${ }^{53}$ das von manchen als "Diskriminierung" empfunden sein mag. So Matthias Triebel, Europa und die Kirchen, NomoK@non-Webdokument, RN 4,

http://www.uni-tuebingen.de/kirchenrecht/nomokanon/abhandlungen/004.htm

${ }^{54}$ Siehe dazu samt Verweisen Matthias Triebel, Europa und die Kirchen, loc.cit., RN

$4 \mathrm{ff}$.

${ }^{55}$ So Siegbert Alber, Die Charta der Grundrechte der Europäischen Union unter besonderer Berücksichtigung der Religionsfreiheit, in Religion, Staat, Gesellschaft...., 293-308, 302.

${ }^{56}$ Auch auf der politischen Ebene. Angeblich soll das Protokoll in Amsterdam deshalb auf den Stand eines Protokolls gedrückt worden sein, weil Frankreich, Belgien und die Niederlanden dies aus Laizitätsgründen für notwendig hielten und weil England und die skandinavischen Länder meinten, dass eine Aufnahme in den Vertrag, die Verfassungsqualität des Vertrages unterstreichen könne. So zumindest Bérengère Massignon, Regulation of religious diversity by the institutions of the $E$ uropean Union: from confrontation of national exceptions to the emergence of a European model, website des Hartford Institute for Religion Research,

http://hirr.hartsem.edu/sociology/sociology_online_articles_massignon.htm

${ }^{57}$ Vgl. Dazu etwa das W. Burton und M. Weninger (Hrsg), Rechtliche Aspekten der Beziehung zwischen der künftigen Europäischen Union und den Glaubens- und Überzeugungsgemeinschaften, Europäische Kommission, working paper 2002. vgl. Auch etwa die Initiative „Eine Seele für Europa“, die aus der EU Budgetlinie A 3024 finanziert wurde.

58 Vgl. Charta Entwurf vom 8. März 2000, Charta Dokument 4149/00 Convent 13

${ }^{59}$ Es ist interessant, dass dies ein Einschub ist, der vom zweiten Konvent vorgenommen wurde und insofern die ursprüngliche Präambel der Charta abänderte. Siehe für die Erläuterungen des ersten Konvents: CHARTE 4473/00, S.12.

${ }^{60}$ Die Konsequenz findet seine Grenzen am Diskriminierungsmerkmal der Sprache: Art. 13 EG räumt der Union keine Kompetenz zur Diskriminierungsbekämpfung in diesem Bereich ein, obwohl auch die Diskriminierungen aufgrund der Sprache nach der Grundrechtecharta verboten sind. Diese Inkonsequenz wurde leider auch im Verfassungsvertrag beibehalten. Vgl. dazu die Erklärung von Ljouwert des EBLUL (European Bureau of Lesser Used Languages).61. Siehe dazu etwa Lisa Waddington und Mark Bell, More equal than others: distinguishing European Union equality directives, 38 Common Market Law Review (2001), 587 oder Gabriel N.Toggenburg, The Race Directive: A New Dimension in the Fight against Ethnic Discrimination in Europe, in European Yearbook on Minority Issues 2002, The Hague, Kluwer, S. 231244.

62 Nach dem explanatory memorandum zur Grundrechtecharta stützt sich dieser Artikel 22 auf Artikel 6 des Vertrags über die Europäische Union und auf Artikel 151 Absätze 1 und 4 EGV in Bezug auf die Kultur und lehnt sich ebenfalls an die Erklärung Nr. 11 zur Schlussakte des Vertrags von Amsterdam betreffend den Status der Kirchen und weltanschauliche Gemeinschaften an. Siehe CHARTE 4473/00, 23.

${ }^{63} \mathrm{Vgl}$. aber bereits die Zielbestimmung in Art 3 Abs. 3 des Verfassungsvertrages: , Die Union wahrt den Reichtum ihrer kulturellen und sprachlichen Vielfalt und sorgt für den Schutz und die Entwicklung des kulturellen Erbes Europas."

${ }^{64}$ Die Christopherson Klausel zielt darauf die nationale Identität zu schützen wie sie in der „constitutional and political structure .... including regional and local subdivisions, administration and enforcement where not exceptionally otherwise provided in the Treaties, State/church relations, policy with regard to distribution of income and maintaining or improving social welfare benefits, the sole right to impose personal taxes, etc" zum Ausdruck kommt. Siehe Arbeitsgruppe V, WD 5, 11 Juli 2002, S. 2.

65 Das entsprechende Protokoll für Malta (Protokoll Nummer 7) liest sich wie folgt: Der Vertrag über die Europäische Union, die Verträge zur Gründung der Europäischen Gemeinschaften sowie die Verträge und Akte zur Änderung oder Ergänzung der genannten Verträge berühren nicht die Anwendung innerstaatlicher Rechtsvorschriften über den Schwangerschaftsabbruch im Hoheitsgebiet Maltas." Siehe ABI. L 236 vom 23. September 2003, S. 947.

${ }^{66}$ Protokoll Nr. 33 zum Vertrag zur Gründung der Europäische Gemeinschaft) (02.10.1997), Amtsblatt Nr. C 340 vom 10/11/1997 S. 0110.

67 Siehe etwa http://www.ouestfrance-ecole.com/accueil detail.asp?idDOC=2138

${ }^{68}$ Siehe dazu näher Gabriel N. Toggenburg, Unification via Diversification - what does it mean to be "united in diversity"?, in EUMAP feature „Enlargement Day“, 1 may 2004, http://www.eumap.org/articles/content/98/982

69 So das quasi outgesourcte" Menschenrechts Ÿberwachungsnetz der EU, das E.U. Network of Independent Experts in Fundamental Rights. Siehe dazu den Report on the Situation of Fundamental Rights in the European Union and its Member States in 2002 (Luxembourg: Office for Official Publications of the E.C., 2003), Volume 1, auf S. 175, oder

http://europa.eu.int/comm/justice_home/cfr_cdf/doc/rapport_2002_en.pdf . Für eine diesbezüglich viel zurückhaltendere Einschätzung siehe Bruno de Witte, The 
constitutional resources for an EU minority protection policy in Gabriel N. Toggenburg, Minority protection and the enlarged European Union: The way forward (Arbeitstitel), im Erscheinen, 2004, Budapest/New York, LGI Books.

${ }^{70}$ Abgesehen vom erwähnten Diskriminierungsschutz des aktuellen Art. 13 EG der aber wohl auch dem Sozialrecht zuzuordnen ist.

${ }^{71}$ Eine umfassende Sammlung religionsrelevanter EU-Normen findet sich unter: http://www.uni-trier.de/ ievr/EUreligionsrecht/eureligion_de.pdf

72 So Paul Kirchhof, der unverzichtbare Kern des deutschen Staatskirchenrechts und seine Perspektive im EU-Gemeinschaftsrecht, in Axel Feiherr von Campenhausen und Christoph Link (Hrsg.) Kirchenrecht zwischen Grundgesetz und EU Gemeinschaftsrecht, Peter Lang, Frankfurt 2003, 147-179, 155.

${ }^{73}$ Manche angebliche „Brüsseler Überregulierung“ ist allerdings schier erfunden. So etwa die britische Mär, Brüssel werde gegen das Kirchenläuten tätig werden Diese Geschichte geht anscheinend auf einen Pfarrer zurück, der Angst hatte, dass sich Nachbarn wegen des lauten Läutens an den Gerichtshof in Strassburg (also des Europarates) wenden könnten. Vgl. Daily Telegraph vom 17 Oktober 2002, S. 7.

${ }^{74} \mathrm{Vgl}$. dazu Hennig Kahlert, Personenbezogene Daten im Internet, in European Law Reporter, 11 (2003), S. 432-437.

${ }^{75}$ Dass die Christopherson Klausel dieser Funktion dienen sollte, ergibt sich auch aus einer Stellungnahme von Herrn Altmaier: „The proposal from Mr. Christophersen, to expand art. 6 par. 3 EU-Treaty (the Union shall respect the national identities of its Member States; Union Model) would have as effect an additional safeguard for the Member States with regard to the side-effects, the exercise of "functional powers" could have on their internal structures and national competencies. Such a clause would not automatically mean that functional powers would have no effect at all in the listed areas, but couldt limit or even exclude some "negative“ effects of EU-action in these fields. The EU-legislator would have to take it into account when preparing and adopting legislation, the ECJ would consider if a contested measure (or it's effects) would be in line with the requirements of the "Christopherson-clause". To this effect, it seems to bee appropriate, to move Art. 6 par. 3 EU-Treaty to the new competence-title in order to clarify that it has not just political but also legal importance." Siehe Dokument WD 20 , Arbeitsgruppe V, 4. September 2002

${ }^{76}$ Im EFTA System fehlen etwa solche „Bannmeilen“ gegen ungewünschte Effekte der negativen Integration. Die den Binnenmarkt beschränkende Steuerpolitik zum Schutz der isländischen, identitätsbegründenten Amtssprache fiel etwa unter das Schaffot des Efta Courts. Dieser "entschuldigte" sich dafür mit dem Verweis, dass das Abkommen des Europäischen Wirtschaftsraumes (EWR) eben keine vergleichbaren „Achtungsklauseln“ wie Art 151 EG oder Art 6 EU enthalte. Siehe Gabriel N. Toggenburg, Sprache versus Markt: ist die EFTA vielfalts- oder einfalls- los?, in European Law Reporter 6/2002, 217-223.

${ }^{77}$ Vgl. dazu im Verfassungsvertrag: Art. 9 und Art. III-160 sowie das Protokoll über die Rolle der nationalen Parlamente in der Europäischen Union.

${ }^{78}$ Gerhard Robbers, Europa und die Kirchen, in: Bernhard Nacke (Hrsg), Kirche in Staat und Gesellschaft, Mainz 1998, 173-181, 178.

79 Diese Metapher wird des Öfteren gebraucht (vgl. etwa Hans Graf Huyn, Drei Hügel: Das Fundament Europas, in Otto v. Habsburg et al. (Hrsg.), Grundwerte Europas - Fundamente der Einigung, Stocker Verlag, Graz 1994, S. 9-38) und scheint au Theodor Heuss zurückzugehen.

${ }^{80}$ Vgl. Ludger Kühnhardt, Europas Identität und die Kraft des Christentums, ZEI discussion paper C 60,2000, S. 4

${ }^{81}$ Rede des Staatspräsidenten der Tschechischen Republik am 8. März 1994 vor dem Europäischen Parlament in Straßburg

${ }^{82}$ Die Rede fand Eingang in die so genannte Charter der Europäischen Identität, welche von der Europa Union Deutschland in Lübeck am 28. Oktober 1995 beschlossen wurde (siehe http://www.europaweb.de/europa/02wwswww/203chart/ chartade.htm).

${ }^{83}$ Siehe die Antwort auf die schriftliche Frage E-2413/01 vom 3. September 2001.

${ }^{84}$ Siehe die Antwort auf die schriftliche Frage E-3371/98 vom 16. November 1998, die die Maßnahmen des Rates beschreiben.

${ }^{85}$ Siehe die Antwort auf die schriftliche Frage E-3192/00 vom 16. Oktober 2000, welche entsprechendes Engagement der troika bestätigt.

${ }^{86}$ Siehe die Antwort auf die schriftliche Frage P-2481/01 vom 5 September 2001, welche den Einsatz der EU Troika für Dr Yunis Shaikh beschreibt, der wegen Verstoß gegen das pakistanische Blasphemie Gesetz zum Tode verurteilt wurde.

${ }^{87}$ EU Statement on Freedom of Religion or Belief; RC.DEL/103/99 23 September 1999; Review Conference Human Dimension, on 23 September 1999.

See http://www.cesnur.org/testi/EU stat.htm

88 Siehe dazu etwa den vergleich in Lasia Bloß. European Law of ReligionOrganizational and institutional analysis of national systems and their implications for the future European Integration Process, Jean Monnet Working Paper 13/03, http://www.jeanmonnetprogram.org/papers/03/031301.html

${ }^{29}$ So J.H.H. Weiler wiederkehrend in seinen vier Argumente gegen die Formulierung der Präambel im Entwurf des Verfassungsvertrages, Un' europa cristiana, op.cit., insb. S. 68.

${ }^{90}$ Dieser "soluzione polacca, hat sich auch J.H.H. Weiler angeschlossen, op.cit., S 71

${ }^{91}$ So im Ergebnis auch Roberto Toniatti, L'Europa, dio, diritti di tutti, in II Mattino, 20. Februar 2003. Anderer Ansicht etwa Matthias Belafi, der im Zusammenhang des 
polnischen Vorschlages von einer „wirklichen Gleichberechtigung“ von Gläubigen und Nichtgläubigen spricht. Matthias Belafi, a.a.O., S.3. J. Weiler sieht in der polnischen Formel einen wertvollen "terzo approccio“, den man in der Verfassung verankern könnte. J.H.H. Weiler, Un' europa cristiana, op.cit., S. 70 und 71.

92 Die Hälfte der Verfassungen der EU Mitgliedstaaten haben keine Präambel (und zwar jene Belgiens, Dänemarks, Finnlands, Italiens, Luxembourgs, der Niederlanden, Österreichs und Schwedens). Vgl. Armin von Bogdandy, The Preamble, in Bruno de Witte, Ten reflections on the Constitutional treaty for Europe, European University Institute, Florence 2003, S. 3-10, 4.

${ }^{93}$ Orlando Budelacci, Gott, die Griechen und die neue EU-Verfassung - philosophische Reflexionen zur Verfassungspräambel. Erscheint im Sammelband des Forschungskolloquiums: „Legitimationsgrundlagen der Europäischen Union“ (Philosophisches Seminar der Universität Zürich.)

${ }^{94} \mathrm{Vgl}$. etwa A. Angenendt, Die religiösen Wurzeln Europas, in Das gemeinsame Haus Europa (herausgegeben vom Museum für Völkerkunde Hamburg), 1999, S. $481-488$.

${ }^{95}$ Siehe B. F. Nelsen, J. L. Guth und C. R. Fraser, Does Religion Matter?

Christianity and Public Support for the European Union, in European Union Politics, 2(2001), S. 191-217.

${ }^{96}$ So Robert Spaemann, Grenzen - zur ethischen Dimension des Handelns, KlettCotta, Stuttgart 2001, S. 278 und 279.

\section{Literaturverzeichnis}

Alber, Siegbert: Die Charta der Grundrechte der Europäischen Union unter besonderer Berücksichtigung der Religionsfreiheit, in Religion, Staat, Gesellschaf, S. 293-308.

Alihabai-Brown, Yasmin: What perspectives for Islam and Muslims in Europe? An overview, Commentary of the European policy Centre, February 2004,

http://www.theepc.net/en/default.asp?TYP=TEWN\&LV=187\&see= $y \& t=\& P G=T E W N / E N /$ detail $\& \mathrm{l}=2 \& A \mathrm{l}=346$

Angenendt, A: Die religiösen Wurzeln Europas, in Das gemeinsame Haus Europa (herausgegeben vom Museum für Völkerkunde Hamburg), 1999, S. 481 - 488.

Avci, Gamze: Putting the Turkish EU candidacy into context, 7 (2002) European Foreign Affairs Review 91, S. 102.

Bausback, Winfried: Religions- und Weltanschauungsfreiheit als Gemeinschaftsgrundrecht, in Europarecht, 2 (2000), S. 261-273.

Belafi, Matthias: Gott in die Europäische Verfassung?, Positionspapier des Zentrums für angewandte Poltikforschung (CAP),

http://www.cap.uni-muenchen.de/aktuell/positionen/ 2003_11_eu_religion.htm

Bloss, Lasia: European Law of Religion- Organizational and institutional analysis of national systems and their implications for the future European Integration Process, Jean Monnet Working Paper 13/03, http://www.jeanmonnetprogram.org/papers/03/031301.html 
Bogdandy, Armin von: The Preamble, in Bruno de Witte (ed.), Ten reflections on the Constitutional Treaty for Europe, European University Institute, Florence 2003, S. 3-11.

Budelacci, Orlando: Gott, die Griechen und die neue EU-Verfassung philosophische Reflexionen zur Verfassungspräambel. Erscheint im Sammelband des Forschungskolloquims "Legitimationsgrundlagen der Europäischen Union" des Philosophischen Seminars der Universität Zürich.

Burton, Win und Weninger, Michael (Hrsg): Rechtliche Aspekten der Beziehung zwischen der künftigen Europäischen Union und den Glaubens- und Überzeugungsgemeinschaften, Europäische Kommission, working paper 2002.

De Witte, Bruno: The constitutional resources for an EU minority protection policy in Gabriel N. Toggenburg, Minority protection and the enlarged European Union: The way forward (Arbeitstitel), im Erscheinen, 2004, Budapest/New York, LGI Books.

De Witte, Bruno und Toggenburg, Gabriel N.: Human rights and membership of the European Union, in Steve Peers und Angela Ward, The EU Charter of Fundamental rights, Hart, Oxford 2004, S. 59-82.

Hein, Martin: Gott in der Verfassung, abrufbar unter http://www.ekkw.de/ bischof/publikationen.html?publikationen/gott-verfassung/index.html

Hoerster, Norbert (Hrsg.): Klassische Texte der Staatsphilosophie, 10. Auflage 1999, DTV München.
Huyn, Graf Hans: Drei Hügel: Das Fundament Europas, in Otto v. Habsburg et al. (Hrsg.), Grundwerte Europas - Fundamente der Einigung, Stocker Verlag, Graz 1994, S. 9-38.

Jayme, Erik: Multicultural Society and Private Law. German experiences, Saggi, conferenze e seminari, numero 33 , Centro di studi e ricerche di dirito comparato e straniero, Roma 1999.

Kagan, Robert: Macht und Ohnmacht. Amerika und Europa in der neuen Weltordnung, Siedler Verlag, München 2003.

Kahlert, Hennig: Personenbezogene Daten im Internet, in European Law Reporter, 11 (2003), S. 432-437.

Kirchhof, Paul: Der unverzichtbare Kern des deutschen Staatskirchenrechts und seine Perspektive im EU-Gemeinschaftsrecht, in Axel Feiherr von Campenhausen und Christoph Link (Hrsg.) Kirchenrecht zwischen Grundgesetz und EU Gemeinschaftsrecht, Peter Lang, Frankfurt 2003, S. 147-179.

Kopeinig, Margaretha und Kotanko, Christoph: Eine europäische Affäre, Wien 2000, Czernin Verlag.

Kühnhardt, Ludger, Europas Identität und die Kraft des Christentums, ZEI discussion paper C 60, 2000.

Massignon, Bérengre: Regulation of religious diversity by the institutions of the European Union: from confrontation of national exceptions to the emergence of a European model, website des Hartford Institute for Religion Research, http://hirr.hartsem.edu/sociology/ sociology_online_articles_massignon.html 
Nelsen, Brent F. Guth, James L. und Fraser, Cleveland R.: Does Religion Matter? Christianity and Public Support for the European Union, in European Union Politics, 2(2001), S. 191-217.

Piciocchi, Cinzia: Europe faces cultural diversity: towards a European Multicultural Model?, in Francesco Palermo and Gabriel N. Toggenburg (eds.), European constitutional values and cultural diversity, Eurac, Bolzano 2003, S. 25-36.

Robbers, Gerhard: Europa und die Kirchen, in: Bernhard Nacke (Hrsg), Kirche in Staat und Gesellschaft, Mainz 1998, S. 173-181.

Robinson, B.A.: The US national mottos, abrufbar unter: $\mathrm{http}: / / \mathrm{www}$.religioustolerance.org/nat_mott.htm

Rohe, Mathias: IPL as sluice importing Islamic rules in Germany and Europe (Arbeitstitel), in European Yearbook on Minority Issues, EYMI, Volume 3 (2003/4), Kluwer Law International, The Hague, erscheint 2004.

Rohe, Mathias: Der Islam und deutsches Zivilrecht, in Hans-Georg Ebert und Thoralf Hanstein (Hrsg.), Beiträge zum Islamischen Recht, Peter Lang, 2003, S. 35-61.

Schneider, Heinrich: Die Europäische Union als Wertegemeinschaft auf der Suche nach sich selbst, in Die Union 1 (2000), S. 11-48.

Spaemann, Robert: Grenzen - zur ethischen Dimension des Handelns, Klett-Cotta, Stuttgart 2001.
Triebel, Matthias: Religion und Religionsgemeinschaften im künftigen Europäischen Verfassungsvertrag, Die Debatten des Europäischen Konvents, NomoK@non-Webdokument: http://www.nomokanon.de/ abhandlungen/014.htm

Triebel, Matthias: Die Zukunft Europas und der Beitrag der Kirchen. Eine Auswertung der kirchlichen Stellungnahmen gegenüber dem Europäischen Konvent, NomoK@non-Webdokument: http:// www.nomokanon.de/abhandlungen/012.htm.

Triebel, Matthias: Europa und die Kirchen, NomoK@nonWebdokument, http://www.uni-tuebingen.de/kirchenrecht/nomokanon/ abhandlungen/004.htm.

Toggenburg, Gabriel N.: Vertragsänderung im Tandem: Regierungskonferenz und Europäischer Konvent, in European Law Reporter 2002/11, 398-402.

Toggenburg, Gabriel N.: The Race Directive: A New Dimension in the Fight against Ethnic Discrimination in Europe, in European Yearbook on Minority Issues 2002, The Hague, Kluwer, S. 231-244.

Toggenburg, Gabriel N.: Sprache versus Markt: ist die EFTA vielfaltsoder einfallslos?, in European Law Reporter 6/2002, 217-223.

Toggenburg, Gabriel N.: Unification via Diversification - what does it mean to be „united in diversity"?, in EUMAP feature „Enlargement Day“, 1 may 2004, http://www.eumap.org/journal/features/2004/bigday/ diversity/

Toniatti, Roberto: L'Europa, dio, diritti di tutti, in II Mattino, 20. Februar 2003. 
Waddington, Lisa und Bell, Mark: More equal than others: distinguishing European Union equality directives, 38 Common Market Law Review (2001), S. 587.

Weiler, J.H.H.: Un'Europa cristiana, un saggio esplorativo, RCS libri, Milano 2003.

Weiler, J.H. H.: Fin-de-siecle Europe: do the new clothes have an emperor?, in The constitution of Europe, in J.J.Weiler, The constitution of Europe, Cambridge University Press 1999.

\section{BASLER SCHRIFTENZUR EUROPÄISCHEN INTEGRATION}

O Wir bestellen die Schriftenreihe im Jahresabonnement zu CHF 120.-. Das Abonnement verlängert sich automatisch um ein Jahr, wenn es nicht dre

Monate vor Ablauf schriftlich gekündigt wird.

O Wir bestellen folgende Nummern zum Preis von CHF 20.- (Doppelnr 30.-)

$O$ Wir sind an einem Publikationsaustausch interessiert.

O Wir sind an Weiterbildungs-Unterlagen (Nachdiplomkurs) interessiert.

* vergriffen

O Nr. 1 Subsidiarität - Schlagwort oder Kurskorrektur (mit Beiträgen von Flavio Cotti, Jean-Paul Heider, Jakob Kellenberger und Erwin Teufel) (Doppelnummer)*

O Nr. 2 Ein schweizerisches Börsengesetz im europäischen Kontext (Tagungsband/Doppelnummer)*

O Nr. 3 Martin Holland, The European Union's Common Foreign and Security Policy: The Joint Action Toward South Africa*

O Nr. 4 Brigid Gavin, The Implications of the Uruguay Round for the Common Agricultural Policy

O Nr. 6 Urs Saxer, Die Zukunft des Nationalstaates

O Nr. 7 Frank Emmert, Lange Stange im Nebel oder neue Strategie? Die aktuelle Rechtsprechung des EuGH zur Warenverkehrsfreiheit

O Nr. 8 Stephan Kux, Subsidiarity and the Environment: Implementing International Agreements

O Nr. 9 Arbeitslosigkeit (mit Beiträgen von Christopher Boyd, Wolfgang Franz und Jean-Luc Nordmann)

O Nr.10 Peter Schmidt, Die aussenpolitische Rolle Deutschlands im neuen Europa

O Nr.11 Hans Baumann, Möglichkeiten und Grenzen der Sozialen Di-mension nach Maastricht: Das Beispiel der Bauwirtschaft *

O Nr.12 Georg Kreis, Das schweizerische Staatsvertragsreferendum: Wechsel-spiel zwischen indirekter und direkter Demokratie

O Nr.13 Markus Lusser, Die europäische Währungsintegration und die Schweiz 
O Nr.14 Claus Leggewie, Ist kulturelle Koexistenz lernbar?

O Nr.15 Rolf Lüpke, Die Durchsetzung strengerer einzelstaatlicher Umweltschutznormen im Gemeinschaftsrecht (Doppelnummer)

O Nr.16 Stephan Kux, Ursachen und Lösungsansätze des Balkankonflikts: Folgerungen für das Abkommen von Dayton

O Nr.17 Jan Dietze/Dominik Schnichels, Die aktuelle Rechtssprechung des Europäischen Gerichtshofes zum Europäischen Gerichtsstands- und Vollstreckungsübereinkommen (EuGVÜ)

O Nr.18 Basler Thesen für die künftige Verfassung Europas (2. Aufl.)

O Nr.19 Christian Garbe, Subsidiarity and European Environmental Policy: An Economic Perspective

O Nr.20 Claudia Weiss, Die Schweiz und die Europäische Menschenrechtskonvention: Die Haltung des Parlaments 1969-1995

O Nr.21 Gunther Teubner, Globale Bukowina: Zur Emergenz eines transnationalen Rechtspluralismus

O Nr.22 Jürgen Mittelstrass, Stichwort Interdisziplinarität (mit einem anschliessenden Werkstattgespräch)

O Nr.23 William James Adams, The Political Economy of French Agriculture

O Nr.24 Aktuelle Fragen der Wirtschafts- und Währungsunion (mit Beiträgen von Gunter Baer, Peter Bofinger, Renate Ohr und Georg Rich) (Tagungsband/Doppelnummer)

O Nr.25 Franz Blankart, Handel und Menschenrechte

O Nr.26 Manfred Dammeyer/Christoph Koellreuter, Die Globalisierung der Wirtschaft als Herausforderung an die Regionen Europas

O Nr.27 Beat Sitter-Liver, Von Macht und Verantwortung in der Wissenschaft

O Nr.28 Hartwig Isernhagen, Interdisziplinarität und die gesellschaftliche Rolle der Geistes- und Kulturwissenschaften

O Nr.29 Muriel Peneveyre, La réglementation prudentielle des banques dans l'Union Européenne

O Nr.30 Giuseppe Callovi/Roland Schärer/Georg Kreis, Citoyenneté et naturalisations en Europe

O Nr.31 Peter Häberle, Gemeineuropäisches Verfassungsrecht

O Nr.32 Jacques Pelkmans, Europe's Rediscovery of Asia. Political, economic and institutional aspects
O Nr.34 Valéry Giscard d'Estaing, L'Union Européenne: Elargissement ou approfondissement?

O Nr.35 Martin Holland, Do Acronyms Matter? The Future of ACP-EU Relations and the Developing World

O Nr.36 Andreas Guski, Westeuropa - Osteuropa: Aspekte einer problematischen Nachbarschaft

O Nr.37 Matthias Amgwerd, Autonomer Nachvollzug von EU-Recht durch die Schweiz - unter spezieller Berücksichtigung des Kartellrechts (Doppelnr.)

O Nr.38 Manfred Rist, Infotainment oder Sachinformation? Die Europäische Union als journalistische Herausforderung (Doppelnummer)

O Nr.39 Lothar Kettenacker/Hansgerd Schulte/Christoph Weckerle, Kulturpräsenz im Ausland. Deutschland, Frankreich, Schweiz

O Nr.40 Georg Kreis/Andreas Auer/Christoph Koellreuter, Die Zukunft der Schweiz in Europa? Schweizerische Informationstagung vom 15 April 1999 veranstaltet durch das EUROPA FORUM LUZERN

O Nr.41 Charles Liebherr, Regulierung der audiovisuellen Industrie in der Europäischen Union

O Nr.42/3 Urs Saxer, Kosovo und das Völkerrecht. Ein Konfliktmanagement im Spannungsfeld von Menschenrechten, kollektiver Sicherheit und Unilateralismus

O Nr.44/5 Gabriela Arnold, sollen Parallelimporte von Arzneimitteln zugelassen werden? Eine Analyse der Situation in der Europäischen Union mit Folgerungen für die Schweiz

O Nr.46 Markus Freitag, Die politischen Rahmenbedingungen des Euro: Glaubwürdige Weichenstellungen oder Gefahr möglicher Entgleisungen?

O Nr.47/8 Andrew Watt, „What has Become of Employment Policy?“ - Explaning the Ineffectiveness of Employment Policy in the European Union

O Nr.49 Christian Busse, Österreich contra Europäische Union - Eine rechtliche Beurteilung der Reaktionen der EU und ihrer Mitgliedstaaten auf die Regierungsbeteiligung der FPÖ in Österreich

O Nr.50 Thomas Gisselbrecht, Besteuerung von Zinserträgen in der Europäischen Union - Abschied vom Schweizerischen Bankgeheimnis? 
O Nr.51 Uta Hühn, Die Waffen der Frauen: Der Fall Kreil - erneuter Anlass zum Konflikt zwischen europäischer und deutscher Gerichtsbarkeit? EuGH, Urteil vom 11.1.2000 in der Rs. C-283/98, Tanja Kreil/BRD

O Nr.52/3 Thomas Oberer, Die innenpolitische Genehmigung der bilateralen Verträge Schweiz - EU: Wende oder Ausnahme bei aussenpolitischen Vorlagen?

O Nr.54 Georg Kreis, Gibraltar: ein Teil Europas - Imperiale oder nationale Besitzansprüche und evolutive Streiterledigung.

O Nr.55 Beat Kappeler, Europäische Staatlichkeit und das stumme Unbehagen in der Schweiz. Mit Kommentaren von Laurent Goetschel und Rolf Weder.

O Nr.56 Gürsel Demirok, How could the relations between Turkey and the European Union be improved?

O Nr.57 Magdalena Bernath, Die Europäische Politische Gemeinschaft. Ein erster Versuch für eine gemeinsame europäische Aussenpolitik

O Nr.58 Lars Knuchel, Mittlerin und manches mehr. Die Rolle der Europäischen Kommission bei den Beitrittsverhandlungen zur Osterweiterung der Europäischen Union. Eine Zwischenbilanz

O Nr.59 Perspektiven auf Europa. Mit Beiträgen von Hartwig Isernhagen und Annemarie Pieper

O Nr.60 Die Bedeutung einer lingua franca für Europa. Mit Beiträgen von Georges Lüdi und Anne Theme

O Nr.61 Felix Dinger, What shall we do with the drunken sailor? EC Competition Law and Maritime Transport

O Nr.62 Georg F. Krayer, Spielraum für Bankegoismen in der EU-Bankenordnung

O Nr.63 Philippe Nell, China's Accession to the WTO: Challenges ahead

O Nr.64 Andreas R. Ziegler, Wechselwirkung zwischen Bilateralismus und Multilateralismus Das Beispiel der Freihandelsabkommen der EFTAStaaten

O Nr.65 Markus M. Haefliger, Die europäische Konfliktintervention im burundischen Bürgerkrieg, („Arusha-Prozess“)von 1996 bis 2002
O Nr.66 Georg Kreis (Hrsg), Orlando Budelacci (Redaktion): Der Beitrag der Wissenschaften zur künftigen Verfassung der EU. Interdisziplinäres Verfassungssymposium anlässlich des 10 Jahre Jubiläums des Europainstituts der Universität Basel.

O Nr.67 Francis Cheneval, Die Europäische Union und das Problem der demokratischen Repräsentation.

O Nr.68 Politik und Religion in Europa. Mit Beiträgen von Orlando Budelacc und Gabriel N. Toggenburg.
Europainstitut der Universität Basel, Gellertstrasse 27, CH-4020 Basel, Schweiz, Tel. ++41 (0) 613179767 , FAX ++41 (0) 613179766

E-mail: europa@unibas.ch, Internet:www.europa.unibas.ch

\section{Europainstitut der Universität Basel 2004}

Alle Rechte vorbehalten. Nachdruck, auch auszugsweise, sowie die Verbreitung auf elektronischem, photomechanischem oder sonstigem Wege bedürfen einer schriftlichen Genehmigung des Europainstituts. 